\title{
Chapter 10 \\ Electron Beam Technologies \\ for the Joining of High Alloy TRIP/TWIP \\ Steels and Steel-Matrix Composites
}

\author{
Lars Halbauer, Anja Buchwalder and Horst Biermann
}

\begin{abstract}
The use of new, high-alloy TRIP/TWIP steels and the corresponding composite materials requires innovative joining processes. Due to the high power density, the inert working atmosphere and the software-based control, the electron beam is predestined to study different joining strategies. This paper shows how the electron beam can be used as a tool to join high-alloy TRIP/TWIP materials with and without particle reinforcement. Microstructure-property relationships based on the microstructure and tensile tests are established and correlated to the material used. From this, a corresponding joining strategy is derived for each material, which is presented on the basis of various evaluation criteria.
\end{abstract}

\subsection{Introduction}

Modern lightweight constructions are subjected to the conflicting demands for lower weight and higher load-bearing capacity. To overcome these challenges, a composite material was developed which combines good ductility, high strength and high specific energy absorption potential $[3,4,6,54]$. This is achieved by reinforcing a metastable austenitic steel matrix $(\gamma)$ with $\mathrm{MgO}$ partially stabilized zirconia $(\mathrm{Mg}$ PSZ) particles. During deformation between the martensite start $M_{\mathrm{s}}$ - and the $M_{\mathrm{d}^{-}}$ temperature (temperature where $1 \%$ strain induced martensite is formed), the matrix of the composites is able to transform into $\alpha^{\prime}$-martensite. The associated TRIP effect (TRansformation Induced Plasticity) involves an exceptional strain-hardening capac-

L. Halbauer $(\bowtie) \cdot$ A. Buchwalder · H. Biermann

Institute of Materials Engineering, Technische Universität Bergakademie Freiberg,

Gustav-Zeuner-Str. 5,

09599 Freiberg, Germany

e-mail: lars.halbauer@iwt.tu-freiberg.de

A. Buchwalder

e-mail: anja.buchwalder@ww.tu-freiberg.de

H. Biermann

e-mail: biermann@ww.tu-freiberg.de

(C) The Author(s) 2020

H. Biermann and C. G. Aneziris (eds.), Austenitic TRIP/TWIP Steels

and Steel-Zirconia Composites, Springer Series in Materials Science 298,

https://doi.org/10.1007/978-3-030-42603-3_10 
ity with still high ductility under tensile loading [36, 37]. However, the deformation behavior of the matrix material depends strongly on the stacking fault energy (SFE) $[29,41,50]$. At relatively high stacking fault energies $\left(>40 \mathrm{~mJ} / \mathrm{m}^{2}\right)$, the preferred deformation mechanism is movement of dislocations (wavy glide). Stacking fault energies in the range of $20-40 \mathrm{~mJ} / \mathrm{m}^{2}$ favor the formation of deformation twins (TWinning Induced Plasticity, TWIP effect) [29] which is accompanied by a significant increase in ductility. In steels with a stacking fault energy lower than 15-20 $\mathrm{mJ} / \mathrm{m}^{2}$, the TRIP effect occurs [29, 43, 45, 55]. With applied stress, the Mg-PSZ particles can undergo a phase transformation as well, where the tetragonal phase transforms into monoclinic particles [12]. Consequently, a stress field within the matrix is counteracted by the resulting volume expansion of the particle and thus the fracture resistance of the component is further increased [28].

For the evaluation of a potential application, the weldability of the material has to be investigated. According to DIN ISO/TR 581:2007 [11], the term weldability is referred to as the interdependence of three component properties (cf. Fig. 10.1):

Material The weldability depends on the material properties such as their chemical composition (e.g. hardening) and their microstructure (e.g. elimination of precipitation hardening, coarsening of grains). The material properties have a strong dependence on the necessary constructional properties and only a weak dependence on the welding process.

Construction As a generic term, the constructional properties describe the possibility to weld. They are defined by the joint geometry and the type of stress that is applied during or after welding. Constructional properties are strongly dependent on the welding process (which process for which joint geometry) and slightly dependent on the material properties (e.g. metallurgical notches).

Process Finally, the weldability is defined by the process parameters, which are determined by the type of welding process and the inherent welding parameters. The choice of parameters strongly depends on the material properties and weakly depend on the constructional properties.

Comparable to the laser beam (LB), the electron beam (EB) can be applied for a high energy fusion process. The difference to conventional joining approaches is the use of highly accelerated electrons as energy source which allows the application of very high energy densities. The EB as a joining tool allows essential process parameters such as beam power, feed rate or focal point to be set freely and reproducibly. This also makes comprehensive monitoring of the process possible. At the same time, due to the adjustable power density, both deep welding and heat conduction welding can be established to investigate the influence of the welding process. Due to the high positioning accuracy, the dilution can also be precisely controlled in dissimilar weld joints to set the materials properties. In addition, solid state joining processes, such as soldering, can be carried out via the freely programmable, almost inertia-free 


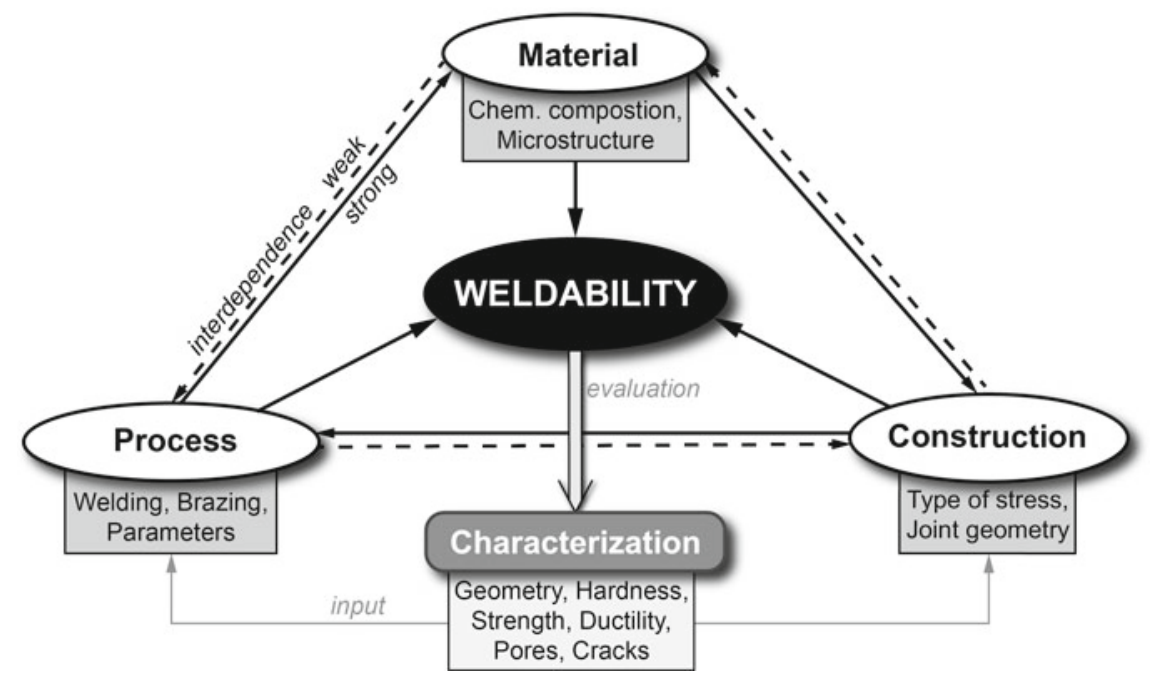

Fig. 10.1 Weldability of TRIP-matrix composites dependent on the material, the construction and the process (according to DIN ISO/TR 581:2007 [11])

deflection of the EB. Oxide and pore formation is significantly inhibited due to the process inherent vacuum atmosphere. However, it should be noted that elements with a high vapor pressure (such as $\mathrm{Mn}$ ) may be able to degas.

For high-alloy (HA) TRIP/TWIP-matrix composites the weldability has not been studied yet. First experiments from Buchwalder et al. show a good weldability of the HA base material but no experiments were carried out on the composite [8]. Thus, only partial information on the weldability of similar steels or composites can be obtained from the literature. Reference materials for the base material are lowalloy (LA) TRIP steels and HA TWIP steels. LA TRIP steels, which mainly consist of ferrite, bainite, martensite and retained austenite, show a significant TRIP effect during deformation and are therefore comparable in terms of mechanical behavior to the HA TRIP steels with low SFE. The welding of LA TRIP steels was carried out with a broad variety of welding processes, such as gas metal arc (GMA) [21, 26], resistance spot [22, 34], friction stir [30], and LB welding [7, 25, 42]. Failure takes place within the heat affected zone of the material $[22,26]$. The welding seam shows a significant increase in hardness (up to $510 \mathrm{HV}$ ) which decreases with decreasing cooling rate [42].

HA TWIP steels can also be welded with various welding processes [33]. During welding, however, the main alloying element manganese has an increasing tendency to evaporate with higher temperatures and lower atmospheric pressure [46]. Mujica et al. showed that the evaporation rate for continuous processes decreases with increasing power density [32]. Typically, up to $2 \mathrm{wt} \% \mathrm{Mn}$ is evaporating during LB welding [27]. Pulsed welding leads to an above-average evaporation rate of manganese. Due to their fully austenitic microstructure and the strong tendency for 
segregation of manganese, HA TWIP steels have a high susceptibility for hot-crack formation [56]. For the hot-rolled alloy Fe-25Mn-3Al-3Si an hardness increase from the base material to the fusion zone from $\approx 1700$ to $2400 \mathrm{HM}$ is reported and explained by the grain refinement after welding [27, 31]. High cooling rates, such as those generated by laser beam welding, can also lead to a significantly increased hardness within the fusion zone (up to $300 \mathrm{HV}$ ) [32]. Due to the evaporation and the lower grain size, the stacking fault energy of the welded seam is locally lower than in the base material. Therefore, the welding seam of HA TWIP steels is not capable to deform as much as the TWIP base material. Accordingly, rupture occurs within the base material where the deformation is concentrated [31, 39, 40, 44].

To the current state of the art, there is no suitable process for joining steel-ceramic composites though. Weigelt et al. proposed a method for the joining of Mg-PSZ reinforced steel matrix composites in the green-body state [53]. While the mechanical properties are outstanding, the process is not applicable for components which are not produced by powder metallurgical processing and rely on welding or brazing. Experiments carried out by Tseng et al. [52] showed a strong negative influence of zirconia during fusion welding. The addition of $\mathrm{ZrO}_{2}$ particles with a diameter $\geq 0.3 \mu \mathrm{m}$ leads to the deterioration of weld seam quality due to crack formation and concave root surface.

With respect to the weldability $\mathrm{Al}-\mathrm{SiC}$ systems can be regarded as alternative composite materials and have already been successfully joined by fusion welding processes, using tungsten inert gas (TIG), LB or EB welding [18, 38]. The melting temperature $\left(T_{\mathrm{M}}\right)$ of the ceramic particles of $\mathrm{Al}$-SiC and TWIP-matrix composites are very close to each other $\left(T_{\mathrm{M}, \mathrm{SiC}}=2730^{\circ} \mathrm{C}, T_{\mathrm{M}, \mathrm{ZrO}_{2}}=2715^{\circ} \mathrm{C}\right)$. The melting point difference $\Delta T_{\mathrm{M}}$ between matrix and reinforcement phase of Al-SiC composites $\left(\Delta T_{\mathrm{M}}=2070^{\circ} \mathrm{C}\right.$ ) is about $775 \mathrm{~K}$ higher than in the case of TRIP-matrix composites with Mg-PSZ $\left(\Delta T_{\mathrm{M}}=1295^{\circ} \mathrm{C}\right)$. However, this is negligible as the temperatures within the keyhole during deep penetration welding can reach temperatures greater than $10^{4} \mathrm{~K}$ [51] during electron beam welding (EBW) and $8 \times 10^{3} \mathrm{~K}$ during laser beam welding (LBW). It was found, that during laser beam welding, the $\mathrm{SiC}$ particles are partially melted, move within the melt pool and form clusters [9]. In contrast, welding with electron beam leads to the ejection of molten material due to the evaporation of $\mathrm{SiC}$ [18]. For amounts higher than $1 \% \mathrm{SiC}$, the ejected volume strongly increased. If the $\mathrm{Al}$ matrix is precipitation hardened, softening occurs in the joining zone. In contrast, the formation of $\mathrm{Al}_{3} \mathrm{C}_{4}$-carbides leads to an increase of hardness. The particle clusters in the weld seam act as locations for stress concentration under external load and cause brittle material failure. This drastically reduces both the strength of the welded joints and the ductility. Rupture occurs within the fusion zone $[18,35]$. It can be derived from past investigations that the joining result for metal-matrix composites strongly depends on the material and the joining process selected.

Consequently, the weldability of TRIP/TWIP-matrix composites with the use of the electron beam is examined in this work. First, the influence of the chemical composition is investigated with similar joints of non-reinforced as-cast steels. Second, the effect of added Mg-PSZ is studied in dissimilar joints with TWIP-matrix compos- 
ites, which was already published in [13-15]. Furthermore, it is investigated how the electron beam can be used to establish a brazing process to join similar TWIP-matrix composites (see [16]). Finally, the loadability is studied under different loading conditions for similar joints.

\subsection{Materials and Methodology}

This section gives an overview about the key parameters used for the experiments. To maintain readability, the parameters that were altered for specific experiments are repeatedly given in the particular sections.

\subsubsection{Electron Beam Facility and Temperature Measurements}

All joining experiments were carried out within an K26-80/15 universal electron beam chamber facility (PRO-BEAM, Neukirchen, Germany) at an ambient pressure of $2 \times 10^{-2}$ mbar. In general, three different processes were applied, i.e. similar electron beam welding (S-EBW), dissimiliar electron beam welding (DS-EBW) and electron beam brazing (EBB). The corresponding parameters are given in Table 10.1 and the sample geometry in Fig. 10.2a.

During S-EBW and DS-EBW the samples were fixed within an clamping device to prevent unwanted movement. It should be noted, that all similar joining experiments were carried out without welding gap (zero gap) to neglect the influence of the joint faces on the welding results. The dissimilar welding experiments were carried out on butt joints. If a beam offset $\Delta x$ was applied, the offset in $\mathrm{x}$-direction was referred to as the distance between the EB and the dissimilar weld joint face. To increase the accuracy of the electron beam position, a notch $\left(0.3 \mathrm{~mm} \times 45^{\circ}\right)$ was applied to the joint edge.

For the brazing experiments, a temperature-controlled power regulation system was used to control the temperature within the energy transfer field (ETF). This

Table 10.1 EB parameters used: acceleration voltage $U_{\mathrm{A}}$, beam current $I_{\mathrm{B}}$, offset to beam current $\Delta I_{\mathrm{B}}$, welding speed $v_{\mathrm{s}}$, holding time $t_{\mathrm{H}}$, beam shift relative to the joint gap $\Delta x$, offset to lens current $\Delta I_{\mathrm{L}}$, oscillation figure $\mathrm{OF}$, diameter of oscillation figure $d_{\mathrm{OF}}$

\begin{tabular}{l|l|l|l|l|l|l|l|l|l}
\hline Process & $U_{\mathrm{A}}(\mathrm{kV})$ & $I_{\mathrm{B}}(\mathrm{mA})$ & $\Delta I_{\mathrm{B}}(\mathrm{mA})$ & $v_{\mathrm{s}}(\mathrm{mm} / \mathrm{s})$ & $t_{\mathrm{H}}(\mathrm{s})$ & $\Delta x(\mathrm{~mm})$ & $\Delta I_{\mathrm{L}}(\mathrm{mA})$ & OF & $d_{\mathrm{OF}}(\mathrm{mm})$ \\
\hline \multirow{2}{*}{ S-EBW } & \multirow{2}{*}{80} & $5 \ldots 180$ & 0 & $1 \ldots 80$ & - & 0 & $-5 \ldots+75$ & \multirow{2}{*}{ Circle } & \multirow{2}{*}{0.5} \\
\cline { 1 - 8 } DS-EBW & & $30 \ldots 110$ & 0 & $5 \ldots 45$ & - & $0 \ldots 0.8$ & $-5 \ldots+30$ & & \\
\cline { 1 - 8 } EBB & 60 & 0 & 70 & - & $43 \ldots 600$ & 0 & +10 & Field & - \\
\hline
\end{tabular}



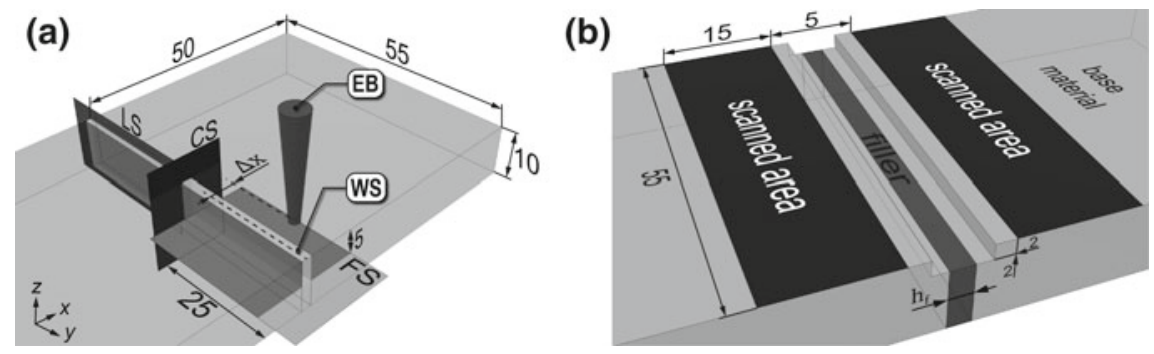

Fig. 10.2 Sample geometry and positioning of EB for a all joining methods with beam offset (if applied) and information about cross-sections (CS), longitudinal-sections (LS) and flat-sections (FS) with respect to the welding seam (WS); b electron beam brazing with material setup and dimensions of the beam interaction field used. All dimensions in ( $\mathrm{mm}$ )

system consisted of a temperature sensor (two-color pyrometer, regulation time $=$ $3 \mathrm{~ms}$ ) and a software that calculated the power output. It was necessary to assign an initial beam current $\left(I_{\mathrm{B}}\right)$ and a beam current offset $\left(\Delta I_{\mathrm{B}}\right)$ for the brazing process. The temperature sensor was placed at the edge between the joint gap and the ETF. Figure $10.2 \mathrm{~b}$ shows the dimensions of the field. During the experiments, the filler gap $\left(h_{\mathrm{f}}\right)$ was increased in the range of 200-1500 $\mu \mathrm{m}$. To ensure constant temperatures alongside the filler gap, an polynomial energy distribution $P_{y}$ according to (10.1) was used with $-27.5<y<27.5$. It was found, that the energy in the center of the scanning area had to be lowered to a minimum of $P_{\min }=0.8$.

$$
P(y)=\left(1-P_{\min }\right)\left(\frac{y}{27.5}\right)^{2}+P_{\min }
$$

An infrared camera was used to evaluate the temperature distribution across the sample width and depth. For a detailed explanation regarding the temperature measurements, please refer to [16].

\subsubsection{Base Materials}

Different types of base materials with the chemical compositions given in Table 10.2 were used for the three joining approaches (S-EBW, DS-EBW, EBB). It should be mentioned, that the amount of alloying elements for the composite material (TWIP+Mg-PSZ) refers to the steel matrix. Accordingly, the chemical composition of the zirconia particles is given in Table 10.3. The base materials were available in three different states:

AC cast-material which was produced by AC-TECH GMBH (Freiberg, Germany) by means of sand casting with a grain size of $\approx 2 \mathrm{~mm}$

HR commercial grade AISI 304 in hot-rolled condition (grain size $\approx 130 \mu \mathrm{m}$ ) 
Table 10.2 Chemical composition (in wt \%) of the basic materials used sorted according to the joining process used. The materials were available in as-cast (AC), hot-rolled (HR) and powder metallurgically produced (PM) (containing $10 \mathrm{vol} \% \mathrm{ZrO}_{2}$ ) conditions

\begin{tabular}{|c|c|c|c|c|c|c|c|c|c|}
\hline Process & Steel name & Short & State & $\mathrm{Fe}$ & $\mathrm{C}$ & $\mathrm{Cr}$ & Mn & $\mathrm{Ni}$ & $\mathrm{Si}$ \\
\hline \multirow[t]{3}{*}{ S-EBW } & $16 \mathrm{Cr}-7 \mathrm{Mn}-3 \mathrm{Ni}$ & $16-7-3$ & \multirow[t]{3}{*}{ Cast } & Bal. & 0.055 & 15.9 & 6.7 & 3.1 & 0.75 \\
\hline & $16 \mathrm{Cr}-7 \mathrm{Mn}-6 \mathrm{Ni}$ & $16-7-6$ & & Bal. & 0.048 & 16.3 & 6.6 & 6.3 & 0.85 \\
\hline & 16Cr-6Mn-9Ni & $16-6-9$ & & Bal. & 0.074 & 15.9 & 6.2 & 9.1 & 0.82 \\
\hline \multirow[t]{2}{*}{ DS-EBW } & AISI 304 & A304 & HR & Bal. & 0.022 & 16.8 & 1.93 & 7.8 & 0.23 \\
\hline & TWIP+Mg-PSZ & MMC & $\mathrm{PM}$ & Bal. & 0.03 & 13.4 & 7.4 & 8.7 & 0.64 \\
\hline \multirow[t]{2}{*}{ EBB } & AISI 304 & A304-B & HR & Bal. & 0.01 & 19.19 & 1.84 & 8.23 & 0.28 \\
\hline & TWIP+Mg-PSZ & MMC & $\mathrm{PM}$ & Bal. & 0.031 & 14.77 & 6.97 & 10.03 & 1.01 \\
\hline
\end{tabular}

Table 10.3 Chemical composition of the Mg-PSZ powder used for producing the MMC

\begin{tabular}{l|l|l|l|l|l|l|l}
\hline (wt\%) & \multicolumn{7}{l}{} \\
\hline $\mathrm{ZrO}_{2}$ & $\mathrm{HfO}_{2}$ & $\mathrm{MgO}$ & $\mathrm{SiO}_{2}$ & $\mathrm{Al}_{2} \mathrm{O}_{3}$ & $\mathrm{CaO}$ & $\mathrm{TiO}_{2}$ & $\mathrm{Fe}_{2} \mathrm{O}_{3}$ \\
\hline Bal. & 1.73 & 3.37 & 2.43 & 0.63 & 0.21 & 0.14 & 0.01 \\
\hline
\end{tabular}

Table 10.4 Chemical composition and nomenclature of the filler material used

\begin{tabular}{l|l|l|l|l|l|l|l}
\hline \multirow{2}{*}{ Filler } & \multirow{2}{*}{$(\mathrm{wt} \%)$} & \multicolumn{5}{l|}{} & $\left({ }^{\circ} \mathrm{C}\right)$ \\
\cline { 3 - 8 } & DIN EN 1044 & $\mathrm{Ni}$ & $\mathrm{Cu}$ & $\mathrm{Si}$ & $\mathrm{Cr}$ & $\mathrm{B}$ & $T_{\mathrm{f}}$ \\
\hline HTL 5 & NI 105 & Bal. & - & 10.1 & 19 & $<0.03$ & 1190 \\
\hline
\end{tabular}

PM composite which was produced by mixing steel and Mg-PSZ powders (SAINTGobaIN, USA, see Table 10.3) by ball milling (100 rpm, $30 \mathrm{~min})$ and subsequent hot pressing $\left(1050^{\circ} \mathrm{C}, 30 \mathrm{~min}\right)$ at FRAUNHOFER IKTS (Dresden, Germany).

Table 10.4 shows both the chemical composition and working temperature $T_{\mathrm{f}}$ of the filler paste (BoEHLER WELDING, Hamm, Germany) used. The composite was produced with a $d_{50}$ of $55 \mu \mathrm{m}$ for the matrix material. Due to local agglomeration of the Mg-PSZ powder, clusters of particles with sizes of up to $20 \mu \mathrm{m}$ were formed during hot pressing.

Before joining, the samples were demagnetized and cleaned with ethanol without additional grinding of the joint faces. For the brazing experiments, the joint faces were ground in direction of gravity. 


\subsubsection{Microstructural Characterization}

After joining, the samples were cut, ground and polished with diamond paste up to $1 \mu \mathrm{m}$. For light optical investigations, the materials were etched either with V2A reagent at a temperature of $60^{\circ} \mathrm{C}$ or with LICHTENEGGER solution. The Electron Backscattered Diffraction (EBSD) investigations were carried out with a LEO 1530 (TESCAN, Czech Republic), an acceleration voltage of $20 \mathrm{kV}, 120 \mu \mathrm{m}$ aperture, $70^{\circ}$ tilting and $17 \mathrm{~mm}$ working distance. Channel 5 (Oxford, HKL) was used as analysis software. Detailed investigations of the connection quality for dissimilar welded materials were carried out on focussed ion beam (FIB) prepared samples at the transmission electron microscope (TEM) JEM 200 FS from JEOL (Japan) at $U_{\mathrm{A}}=$ $200 \mathrm{kV}$ with varying apertures. The investigations were carried out using the analysis software Digital MiCROGRAPH from GATAN and ANALYSIS StATION from JEOL.

\subsubsection{Mechanical Characterization}

The microhardness (HV0.3) of the welding seams was determined with an semiautomatic tester (LECO, Mönchengladbach, Germany). Therefore, hardness indentations with an indentation distance of $0.08 \mathrm{~mm}$ were linearly distributed across the welding seam (WS). After brazing the hardness of the different microstructural constituents within the filler was evaluated using a nanohardness tester Fischerscope (HELMUT FISCHER, Sindelfingen, Germany) with increasing load conditions and a maximum indentation force of $50 \mathrm{mN}$. For all joining processes, the mechanical properties of the material were evaluated in quasistatic tensile tests under displacement control on standard testing machines from HeGEWALD \& PESCHKE (Nossen, Germany) and ZWICK ROELL (Ulm, Germany). Figure 10.5 gives a summary of the geometries of the tensile specimens used.

Table 10.5 Specimen dimensions and the location of the joining zone (JZ) for the quasistatic tensile tests for different joining processes. All dimensions in ( $\mathrm{mm})$

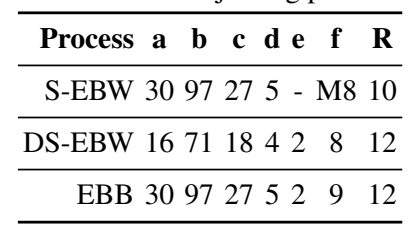

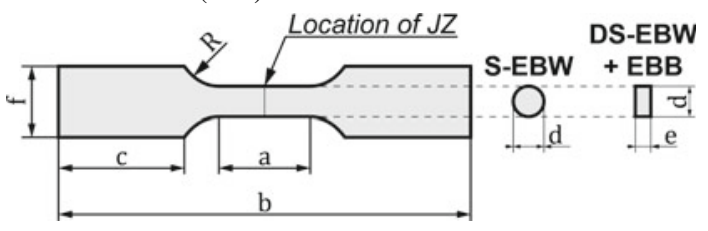




\subsubsection{Non-destructive Testing}

In order to determine the volume defects within the WS, such as pores or shrinkage, $\mathrm{X}$-ray examinations were carried out with an acceleration voltage of $120 \mathrm{kV}$ at a working distance of $90 \mathrm{~cm}$ on parts of the longitudinal sections (see LS, Fig. 10.2a). The samples were placed on an X-ray storage foil and irradiated for an exposure time of 4-8 min (depending on the thickness) with an ERESCO (UK) 200/8 X-ray inspection system.

For the non-destructive ultrasonic immersion tests, a high-frequency USPC 3060 UHF ultrasonic imaging system (INGENIEURBURO DR. HILlGER, Braunschweig, Germany) was used (Fig. 10.3). During the test procedure, the test specimen and the immersion probe were located within a liquid coupling medium (deionized water with $1.25 \%$ Echokor LF anti-corrosion reagent), which ensured uniform coupling. The specimens (height: approx. $10 \mathrm{~mm}$, cf. Fig. 10.2a) were scanned parallel to the yz plane, while the shortest increment size in the $\mathrm{y}$ and $\mathrm{z}$ directions was $13 \mu \mathrm{m}$. A focused broadband transducer (6-12MHz) STS 6 PB 612 P 15 (KARL DEUTSCH, Wuppertal, Germany) with an active diameter of $6 \mathrm{~mm}$ and a focal length of $15 \mathrm{~mm}$ in water was applied.

The focal depth inside the TWIP matrix composite was $\approx 3.1 \mathrm{~mm}$ and the one-way water path between the transducer and the front surface of the specimen was set to $3 \mathrm{~mm}$, respectively. For the acoustic parameters, densities of $7.883 \mathrm{~g} / \mathrm{cm}^{3}$ (AISI 304) and $7.594 \mathrm{~g} / \mathrm{cm}^{3}$ (MMC) and impedances of $45.4 \mathrm{~kg} / \mathrm{m}^{2} \mathrm{~s}$ (AISI 304) and $44.3 \mathrm{~kg} / \mathrm{m}^{2} \mathrm{~s}$ (MMC) were used. The wave velocity was measured using a Panametrics V109 transducer $(5 \mathrm{MHz})$. The Archimedes method was applied for the density measurements of both welded materials.

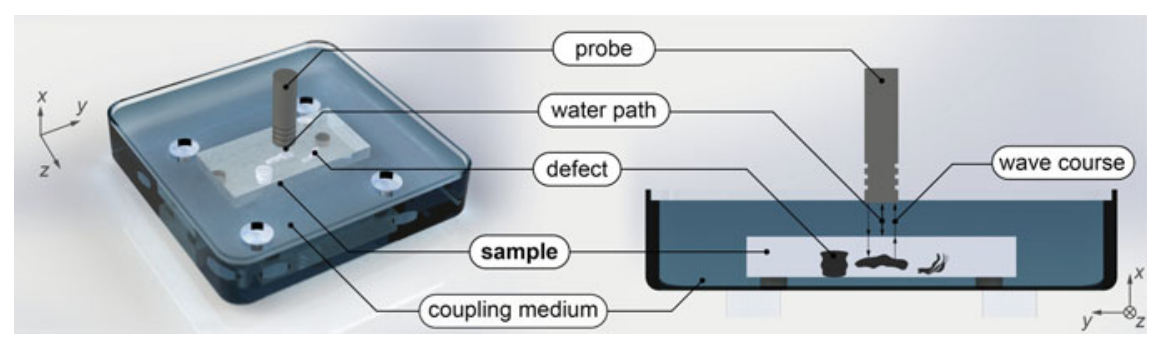

Fig. 10.3 Schematic illustration of the ultrasonic immersion testing method [15] 


\subsubsection{Electron Beam Welding of Similar Joints Without Reinforcement}

\subsubsection{Influence of the Welding Parameters on the Seam Geometry}

In order to investigate the welding behavior of the base material without the influence of the ceramic particles, welding was carried out on cast steels with different nickel contents (cf. Table 10.2). Figure 10.4a shows the evolution of the geometric parameters weld seam depth $\left(t_{\mathrm{WS}}\right)$, weld seam width $\left(b_{\mathrm{WS}}\right)$, nail head width $\left(b_{\mathrm{NH}}\right)$ and face reinforcement $(h)$ as a function of the beam current for a constant welding speed of $10 \mathrm{~mm} / \mathrm{s}$.

(a)

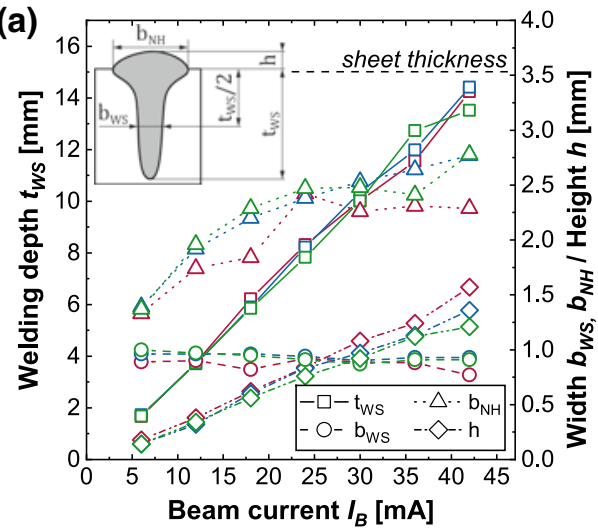

(c)

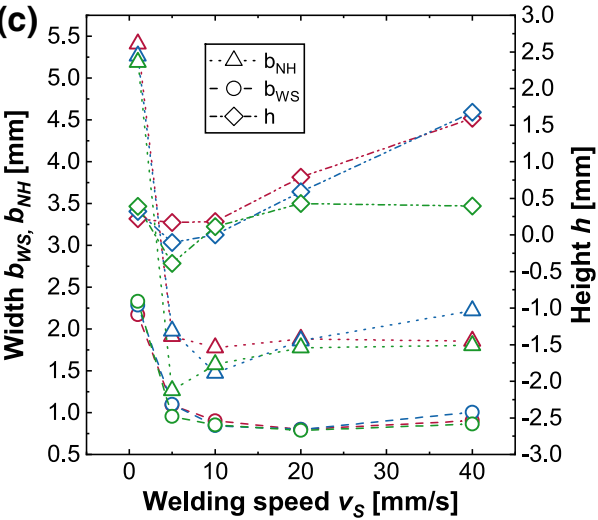

(b)

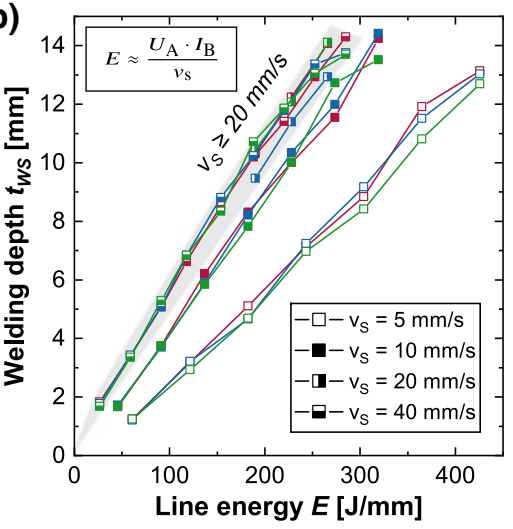

(d)

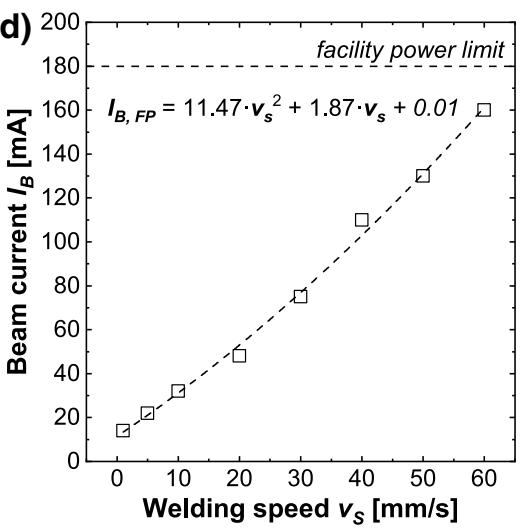

Base materials: $-16-7-3$

16-7-6 16-6-9

Fig. 10.4 Influence of the welding power on the weld seam geometry depending on a the beam current $I_{\mathrm{B}}$ for $v_{\mathrm{s}}=10 \mathrm{~mm} / \mathrm{s} ; \mathbf{b}$ the line energy $E$ and the welding speed $v_{\mathrm{s}} ; \mathbf{c}$ the welding speed during full penetration welding; $\mathbf{d}$ the beam current required for full penetration $\left(I_{\mathrm{B}, \mathrm{FP}} ; t_{\mathrm{WS}}=10 \mathrm{~mm}\right)$ at different welding speeds 
In the examined beam current range the welding depth is directly proportional to the beam current. Since the welds were placed in $15 \mathrm{~mm}$ thick sheets, the selected test parameters did not result in full penetration welding. As a result, the welding depth exhibits fluctuations which depend on the welding speed. At $5 \mathrm{~mm} / \mathrm{s}$ the standard deviation of the welding depth and the maximum depth difference were determined to $0.49 \mathrm{~mm}$ and $1.59 \mathrm{~mm}$, respectively. For higher welding speeds, the fluctuation of the welding depth decreases to an average of $0.11 \mathrm{~mm}$ and a maximum of $0.44 \mathrm{~mm}$. According to Huang et al. [17], this is caused by protuberances formed by the recoil pressure within the keyhole, leading to irregular temperature distributions within the capillary. Based on these results, no clear tendency could be derived with regard to the differences in welding depth between the individual test materials. With regard to the welding depth, all three investigated materials showed the same tendency and almost identical welding depths could be achieved. The width of the weld seam of all materials exhibited only a slight decrease with increasing beam current. This was attributed to the formation of the keyhole even at low power inputs.

To evaluate the influence of the welding speed and the beam current on the welding depth, the line energy (cf. Fig. 10.4b) was calculated after (10.2) with an efficiency $k \approx 1$.

$$
E=k \cdot \frac{U_{\mathrm{A}} \cdot I_{\mathrm{B}}}{v_{\mathrm{s}}}
$$

For welding speeds lower than $20 \mathrm{~mm} / \mathrm{s}$, the welding depth depends on both the welding speed and the line energy. With increasing welding speed, the welding depth becomes independent on the welding speed used. Again, this behavior can be attributed to the deep penetration effect. Lower welding speeds require lower beam currents to achieve the same line energy as with higher welding speeds. Thus, the lower the welding speed, the lower the power density for equal line energies. Since the deep penetration effect depends primarily on the power density, it is only incompletely formed at low welding speeds. In order to produce deep penetration welds at a given energy input per line length, the welding speed has to be increased to compensate the higher required power density. Accordingly, a stable formation of the keyhole occurred above a certain welding speed threshold of $20 \mathrm{~mm} / \mathrm{s}$. At higher welding speeds only the welding depth is increased proportional to the beam power, while the other geometrical parameters remain nearly constant.

In most application-relevant processes, it is necessary to produce a weld seam over the entire sheet thickness with a single pass (full penetration welding). For this purpose, tests were carried out in which the beam current was increased for various welding speeds until the root was completely formed. The beam current needed for full penetration $\left(I_{\mathrm{B}, \mathrm{FP}}\right)$ is shown in Fig. $10.4 \mathrm{~d}$ as a function of the welding speed. The fitting function was a parabola and proved to be valid for all three investigated materials. Experimental practice has also shown that the fit was suitable for both interpolation and extrapolation of beam currents.

In full penetration welds the welding depth is constant for all welding speeds (cf. Fig. 10.4c). With increasing welding speed from 1 to $10 \mathrm{~mm} / \mathrm{s}$, both the seam and 
(a)

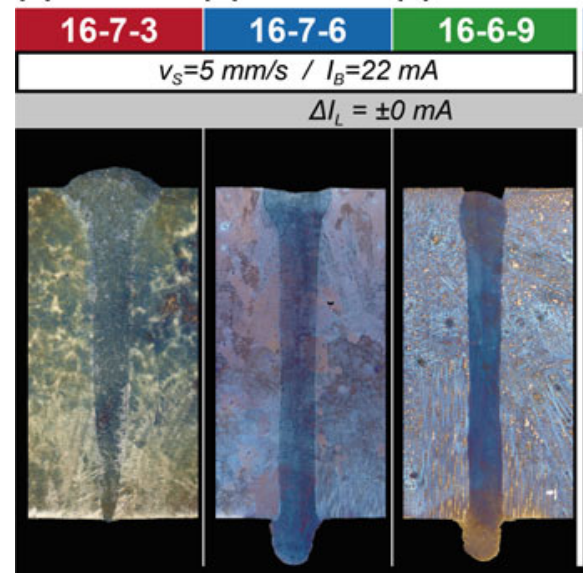

(d) 16-7-6

Fig. 10.5 Macroscopic appearance of the welding seam dependent on the welding speed, the base material and the focal plane

the nail head width decreased independent of the base material used. A reason for this was the limited sample volume used in the experiments. At low welding speeds a significant heat build-up occurred which contributed to the widening of the weld seam in the keyhole area. Although an influence on the welding seam width could have been expected due to differences in the thermal conductivity of the samples (due to the varying nickel content), no clear correlation could be found between the weld width and the material used. This was attributed to the fact that the seam width varies over the seam length due to the keyhole oscillation. Consequently, the seam widths fall within a scatter band. At a welding speed of $10 \mathrm{~mm} / \mathrm{s}$, a beam current of $32 \mathrm{~mA}$ was necessary to achieve full penetration. This was very similar to the threshold of the beam current $\left(I_{\mathrm{Th}}=25 \mathrm{~mA}\right)$, that was found for a stable keyhole welding in the experiments with increasing beam current (cf. Fig. 10.4a). Due to the limitation of $t_{\mathrm{WS}}$, welding speeds $>10 \mathrm{~mm} / \mathrm{s}$ led to a slight increase of $b_{\mathrm{WS}}$, while $b_{\mathrm{NH}}$ remained nearly constant.

\subsubsection{Macroscopic Appearance of the Welding Joints}

Figure 10.5 shows representative cross sections of the three materials welded with different welding speeds and focal offsets. It is shown that the steel 16-7-3 was barely fully penetrated at a beam current of $22 \mathrm{~mA}$ (Fig. 10.5a). An increasing nickel content leads to a stronger formation of the root face and an increasing root convexity (Fig. 10.5a-c). Steel 16-6-9 already shows undercuts (cf. Fig. 10.5c). At the same time, the V-shape of the seams decreases with increasing nickel content. While steel 16-7-3 still has a pronounced nail head due to its higher thermal conductivity, steel 

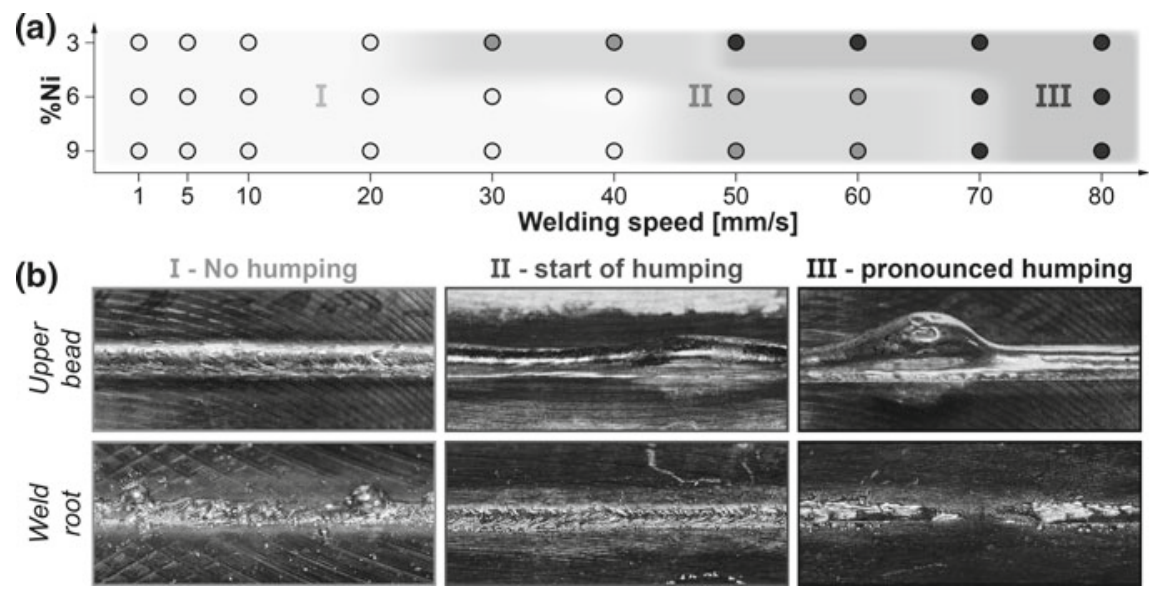

Fig. 10.6 a Representative appearance of upper bead and weld root for different humping tendencies; b humping tendency dependent on the welding speed for the three high alloy steels

16-6-9 shows almost completely parallel fusion faces. This is attributed to the fact that $I_{\mathrm{B}, \mathrm{FP}}$ for the formation of the keyhole has been reached and slightly exceeded for steels 16-7-6 and 16-6-9 respectively. On the other hand, higher beam currents would have been necessary for 16-7-3 steel to increase the deep penetration effect.

This effect disappears at higher welding speeds, so that all welds look as in Fig. $10.5 \mathrm{~d}$ at $40 \mathrm{~mm} / \mathrm{s}$. They exhibit nearly parallel fusion faces and a pronounced nail head formation. The reason for this is the increasing power density, which produces a keyhole at higher welding speeds independent of the material selected. To prove the assumption of the correlation between power density and the deep penetration effect, welds were carried out with a strong defocus (cf. Fig. $10.5 \mathrm{e}, \Delta I_{\mathrm{L}}=+75 \mathrm{~mA}$ ). It was observed that a reduction of the power density resulted in a significant decrease of the welding depth and an increase of the seam width (cf. Fig. 10.5d, e). The typical seam shape is present, as it is created by heat conduction during GMA or TIG welding. Due to the circular beam oscillation, undercuts are formed on the weld face. Apart from undercuts at individual welding speeds, which were caused by too high beam currents or beam oscillation, no macroscopic defects such as cracks, pores or non-metallic inclusions were detected within the welds.

During the experiments, it was noticed that depending on the welding speed, the formation of humping occurred. Thereby the appearance of the weld face and root could in principle be divided into three stages (I-III), which are illustrated in Fig. 10.6b. In stage I the weld face showed no differences in height except for the typical scaling. Only in the lower bead single material elevations were detected which were caused by the oscillation of the keyhole described above. This represented the humping-free state and the predominant portion of the samples. Stage II was characterized by height differences in the upper caterpillar. The seam scaling was not visible at the weld face and could only be found in the root layer, which in addition 
showed no significant height differences. In stage III typical humping features were observed. For example, the weld seam showed periodic protuberances, an incomplete root face and a considerable proportion of ejected weld metal.

The stages described occurred as a function of welding speed and material (Fig. 10.6a). As expected, the humping started at high welding speed ( $\left.v_{\mathrm{s}} \geq 50 \mathrm{~mm} / \mathrm{s}\right)$. In addition, steel 16-7-3 had a much stronger tendency to hump and already showed signs of humping at a welding speed of $30 \mathrm{~mm} / \mathrm{s}$. Above a welding speed of $50 \mathrm{~mm} / \mathrm{s}$ the material could not be considered weldable due to strong humping effects. The steels 16-7-6 and 16-6-9 showed signs of humping only at $50 \mathrm{~mm} / \mathrm{s}$. The weldability limit for the selected parameter set was found at $60 \mathrm{~mm} / \mathrm{s}$. Above this speed the weldability could no longer be guaranteed.

It is known from the literature [5] that humping starts at a certain welding speed and strongly depends on the welding depth and the alloying elements of the base materials. Therefore, it is pointed out that these results are only valid for the investigated sheet thickness of $10 \mathrm{~mm}$ and have to be re-evaluated for other chemical compositions and/or thicknesses of the base material used.

\subsubsection{Influence of the Welding Parameters on Evaporation}

During DPW, the material is locally molten and vaporized to form a keyhole of plasma surrounded by a molten pool. Elements with low vapor pressure, such as manganese, tend to evaporate during welding which is intensified by the low ambient pressure within the vacuum chamber. It was investigated how the process parameters effect the chemical composition of the welding seam with respect to the base material. Independent of the welding speed, no change of the main alloying elements chromium and nickel was detected. In contrast, manganese exhibited a strong evaporation tendency which was dependent on the welding speed (cf. Fig. 10.7a).
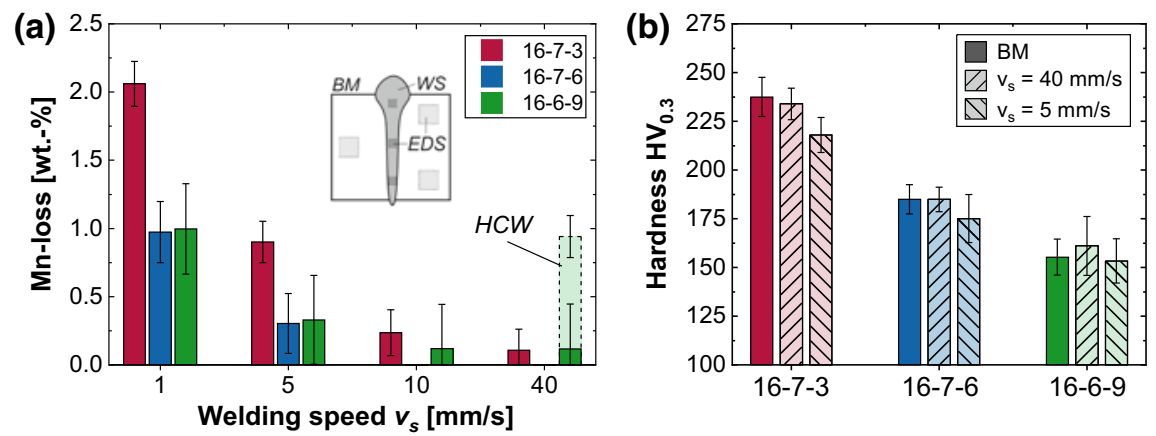

Fig. 10.7 a Manganese loss within the welding seam produced by DPW compared to the base material dependent on the welding speed. HCW: welds produced by $\mathrm{HCW} ; \mathbf{b}$ mean hardness within the base material and the welding seam for two different welding speeds 
At a welding speed of $1 \mathrm{~mm} / \mathrm{s}$, DPW led to a loss of 1-2wt $\%$ manganese. This corresponded to a reduction of the Mn content within the base material by about 17-33\%. However, it should be noted that such welding speeds are rather unusual in practice and have been investigated as extreme values. As the welding speed increased, the manganese loss decreased sharply. For welding speeds of $5 \mathrm{~mm} / \mathrm{s}$ the weld seam exhibited about $0.3-0.9 \mathrm{wt} \%$ manganese loss. At $10 \mathrm{~mm} / \mathrm{s}$ a slight manganese loss of $0.24 \mathrm{wt} \%$ could be detected for the 16-7-3 steel. The manganese loss of the other two steels was in the range of scatter. For welding speeds $>10 \mathrm{~mm} / \mathrm{s}$ no measurable manganese loss could be detected during DPW. Regardless of the welding speed, the 16-7-3 steel always showed the maximum loss of manganese. This was attributed to the increased thermal conductivity and the associated enlargement of the nail head. A proof for this assumption were welding seams, which were produced without keyhole welding (Fig. 10.7a, HCW). With HCW welding, a loss of almost $1 \mathrm{wt} \%$ manganese was measured, which increased with a lower welding speed following the described tendency (up to $2.5 \mathrm{wt} \% \mathrm{Mn}$-loss). It was therefore assumed that the deep welding effect at reasonable welding speeds had no measurable effect on Mn evaporation. Rather, the Mn evaporation was mainly determined by the liquid fraction of the weld seam. There are two effects to be considered:

1. the reduction of the welding speed increases the interaction time of the melt with the environment and more manganese can evaporate.

2. lower welding speeds increase the seam width and, thus, also increasing the area of interaction with the environment.

In order to minimize evaporation, therefore, the lowest possible proportion of HCW like increasing the welding speed or the power density as given in Fig. 10.4 should be set during welding.

To characterize the influence of manganese loss, hardness measurements were performed in both the weld seam and the base material (see Fig. 10.7b). With increasing nickel content the hardness of the base materials was reduced from $240 \mathrm{HVO} 0.3(3 \%$ $\mathrm{Ni})$ to $155 \mathrm{HV} 0.3(9 \% \mathrm{Ni})$. At a welding speed $v_{\mathrm{s}}=40 \mathrm{~mm} / \mathrm{s}$ no significant influence on the hardness was found, which correlates to the low manganese loss. In contrast, welds with a lower feed rate $(5 \mathrm{~mm} / \mathrm{s})$ showed a slight loss of hardness in the weld seam. The decrease in hardness decreased with increasing nickel content. For steel 16-7-3 there was a decrease in hardness of about 20 HV0.3. Steel 16-7-6 showed only a slight decrease in hardness of about $10 \mathrm{HV} 0.3$. The difference in hardness between the weld and the base material was in the range of scatter for steel 16-6-9. These results are in good agreement with the manganese losses which also implies, that low welding speeds should be avoided to minimize the loss of hardness.

\subsubsection{Microstructure of the Welding Joints}

For the investigation of the microstructure, the coloring of the Lichtenegger etching allowed conclusions to be drawn about the primary solidification behaviour of the samples. Typically ferrite $(\delta)$ remains white, austenite solidified primarily from 
the melt $\left(\gamma_{\mathrm{P}}\right)$ becomes blue and austenite, formed by solid phase transformation (secondary austenite, $\gamma_{\mathrm{S}}$ ) is colored brown [48].

According to FACTSAGE calculations, a primary ferritic solidification should be present for all three materials studied [20]. For steel 16-7-3, the primary solidification mode was not clearly recognizable for both the base material and the weld seam (cf. Fig. 10.8a, d). Typical segregation zones around the ferrite were missing. Both the austenite and ferrite were etched by the reagent. Weld seam and base material showed a comparable plate-shaped morphology of the ferrite. In the weld seam, whose appearance was almost independent of the welding speed, dark etched areas were also visible (Fig. 10.8d). These consisted of stress induced martensite which had been formed unavoidably during the preparation routine. It was assumed that the etching process favored the martensitic areas and therefore falsified the typical Lichtenegger etching reaction. However, measurements of the element distribution over the ferrite regions (Fig. 10.9a) showed an opposed distribution of $\mathrm{Cr}$ and $\mathrm{Ni}$, which typically occurs during primary ferritic solidification [49].

For steel 16-7-6 this primary ferritic solidification was very well recognizable in both the base material and the weld seam (cf. Fig. 10.8b, e). Although the ferrite had a dark coloration, it was expectedly located within the dendrite core (DC) surrounded by typical bright segregation zones of the austenitic interdendritic region (IDR). The ferrite possessed a skeletal morphology (or 'vermicular' in American terminology), which was randomly distributed within the former dendrites (Fig. 10.8e). Measurements of the element distribution over single dendrites showed atypical element distributions. As can be seen in Fig. 10.9b, both the DC and the IDR were enriched with $\mathrm{Cr}$. However, areas were found in which there was both an equal and an opposite elemental distribution. According to the authors, this could result from the peritectic

(a)
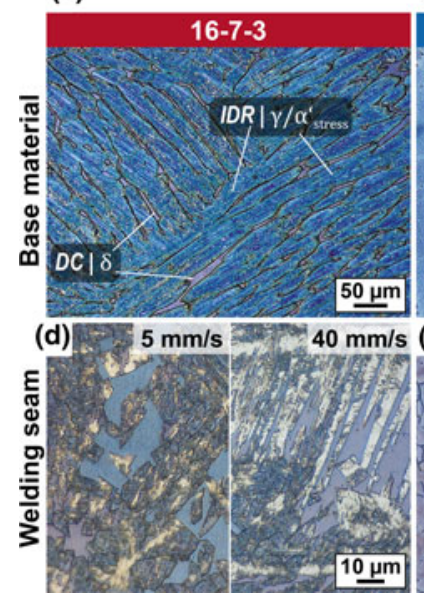

(b)

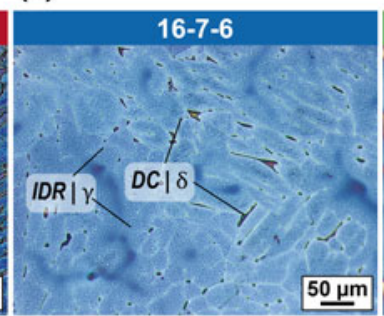

(c)

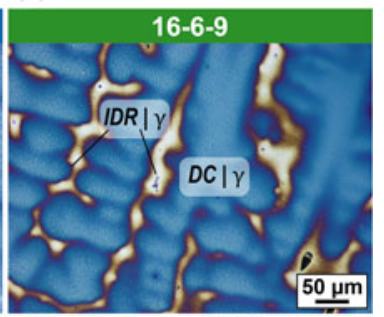

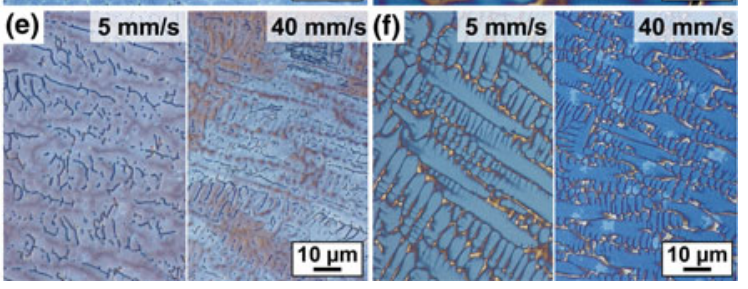

Fig. 10.8 Light optical appearance of the base material and the welding seam $\left(v_{\mathrm{s}}=5-40 \mathrm{~mm} / \mathrm{s}\right)$ for different steels after etching 

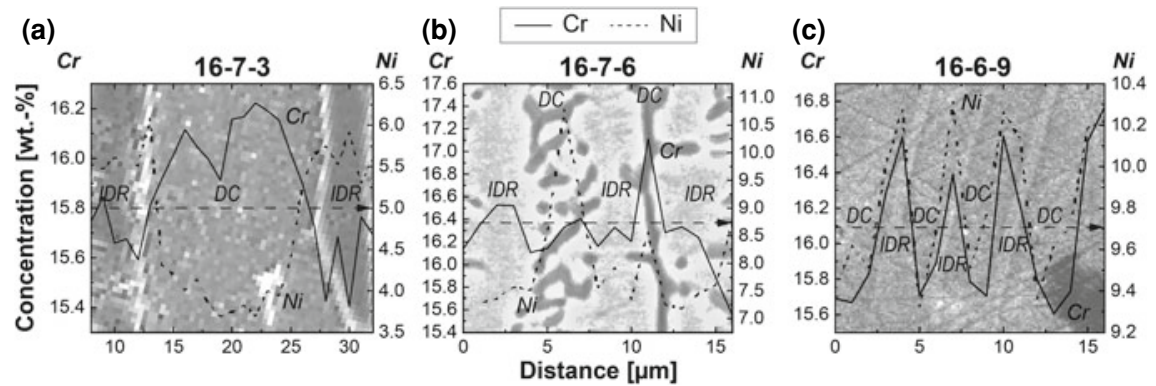

Fig. 10.9 Influence of the base material on the element distribution of $\mathrm{Cr}$ and Ni regarding the dendrite core (DC) and interdendritic regions (IDR) measured by EDS line scans

reaction calculated for both steel 16-7-6 and 16-6-9. It is known from literature [19] that simultaneous crystallization of the $\delta$ and $\gamma$ phases does not occur during technical solidification. Accordingly it is assumed for the 16-7-6 steel that first a ferritic solidification took place which subsequently was followed by a peritectic reaction. In this reaction, the austenite phase was preferred and segregation of $\mathrm{Cr}$ and $\mathrm{Ni}$ took place in opposite as well as in the same direction.

The steel 16-6-9 showed a fully austenitic structure in the base material as well as in the weld seam with clearly recognizable primary austenitic components (cf. Fig. $10.8 \mathrm{c}, \mathrm{f}$ ). The solidification structures were completely dendritic and the IDR had a light coloration without a clearly recognizable phase boundary. During welding the dendritic arm spaceing (DAS) became smaller, otherwise the behavior did not change. In addition, an equidistant distribution of $\mathrm{Cr}$ and $\mathrm{Ni}$ could be detected (Fig. 10.9c), which supported the assumption of the primary austenitic solidification mode (cf. [23]).

In conclusion, the solidification of the steels 16-7-3 and 16-7-6 was classified as ferritic-austenitic (FA) mode, whereas the steel 16-6-9 solidified according to the austenitic-ferritic (AF) mode.

\subsubsection{Mechanical Behavior of the Welding Joints}

The quasi-static behavior of the investigated materials is summarized in Fig. 10.10. A $\delta$ ferrite content of 7.4\% was detected in the base material of the 16-7-3 steel. In the milled samples, about 20-24\% grinding martensite was determined. With increasing strain (up to $12 \%$ engineering strain), the martensite content increased to about 50$65 \%$. This indicated that a TRIP effect was occurring with corresponding martensite formation. For all samples of the steel 16-7-3 less martensite was detected in the base material than in the weld seam. At a welding speed of $5 \mathrm{~mm} / \mathrm{s}$, about $5-10 \%$ less martensite was detected compared to the weld seams welded with $40 \mathrm{~mm} / \mathrm{s}$.

This behavior was attributed to the reduction of the grain size in the weld seam. With increasing welding speed a reduction of the sub-grain size and thus an intrinsic 
(a)
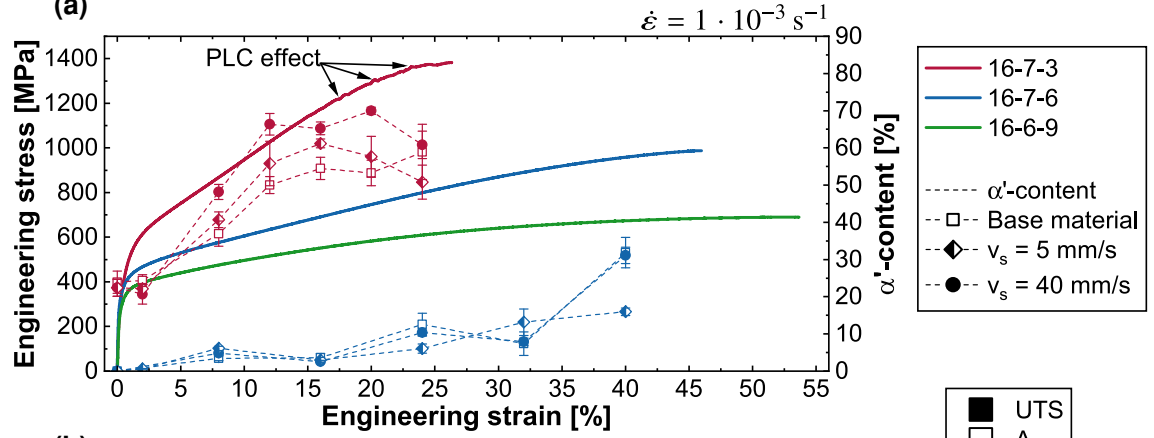

(b)

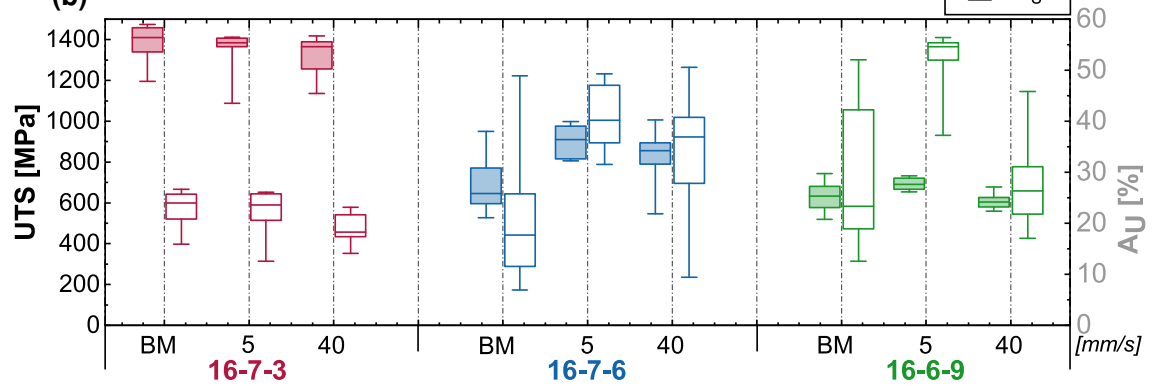

Fig. 10.10 a Representative stress/strain-curves with martensite evolution for the tested materials; b mechanical properties with ultimate tensile strength (UTS) and elongation at UTS $\left(A_{\mathrm{U}}\right)$ dependent on the welding parameters and the base material (BM) used

increase of the SFE could be proven. This shifts martensite formation to higher temperatures, leading to increased martensite formation at room temperature. The typical inflection points of the stress-strain curve were not visible and the Portevin-Le Châtelier effect (visible as serrations in the stress-strain curve, Fig. 10.10a) occurred at higher stress levels.

A slight increase in martensite content was also observed in the 16-7-6 steel (Fig. 10.10a), which contained approximately $1.2 \% \delta$ ferrite in the initial state. However, this was significantly lower than for steel 16-7-3 and no clear influence of the welding parameters on the martensite evolution was observed. Between 32 and $40 \%$ technical strain, samples welded with $40 \mathrm{~mm} / \mathrm{s}$ showed a sharp increase in martensite content to about $30 \%$. Since the base material exhibited the same values, it is assumed that this was an influence of the chemical composition (due to segregation within the as-cast material).

Steel 16-6-9 showed the lowest strain hardening behavior and the highest elongation of all investigated materials (Fig. 10.10a). Neither $\delta$ ferrite nor $\alpha^{\prime}$ martensite could be detected in the base material or in the weld seam.

Independent on the base material and the welding parameters used, all specimens broke outside the welding seam. The steel 16-7-3 exhibited a UTS of about $1400 \mathrm{MPa}$ regardless of the welding condition (cf. Fig. 10.10b). The ductility of the specimens 
decreased slightly at higher welding speed, which could be attributed to the higher amount of martensite. Nevertheless, the data were equivalent within scatter. Steels 16-7-6 and 16-6-9 showed a slight increase in strength after welding of the samples which, however, was also within scatter (cf. Fig. 10.10b). In addition, a strong scatter of elongation values was observed (Fig. 10.10b). After further examination of the broken specimens, it was found that a large number of pores was present in the crosssection of the specimens. They were responsible for the sharp decrease in elongation values and reduced strength in both materials. Accordingly, the maximum strength was achieved in the welded condition. At a lower welding speed $\left(v_{\mathrm{s}}=5 \mathrm{~mm} / \mathrm{s}\right)$, the strength and elongation of the welding joint was higher than for high welding speed $\left(v_{\mathrm{s}}=40 \mathrm{~mm} / \mathrm{s}\right)$. This was attributed to the slightly increased seam width and the higher degassing at low welding speeds. Thus, steel 16-7-6 achieved strengths of about $950 \mathrm{MPa}$ at a maximum elongation of 36-47\%. The steel 16-6-9 exhibited tensile strengths of about $720 \mathrm{MPa}$ at an elongation at rupture of $52-56 \%$.

\subsubsection{Electron Beam Welding of Similar Joints with Reinforcement}

The preliminary investigations showed that the welding process has no negative influence on the mechanical behavior of the AC material. Therefore, the welding result of the composite material with added Mg-PSZ particles was investigated. A hotpressed composite based on steel 16-6-9 with 10\% Mg-PSZ was used. Figure 10.11 shows the cross section of a typical weld.
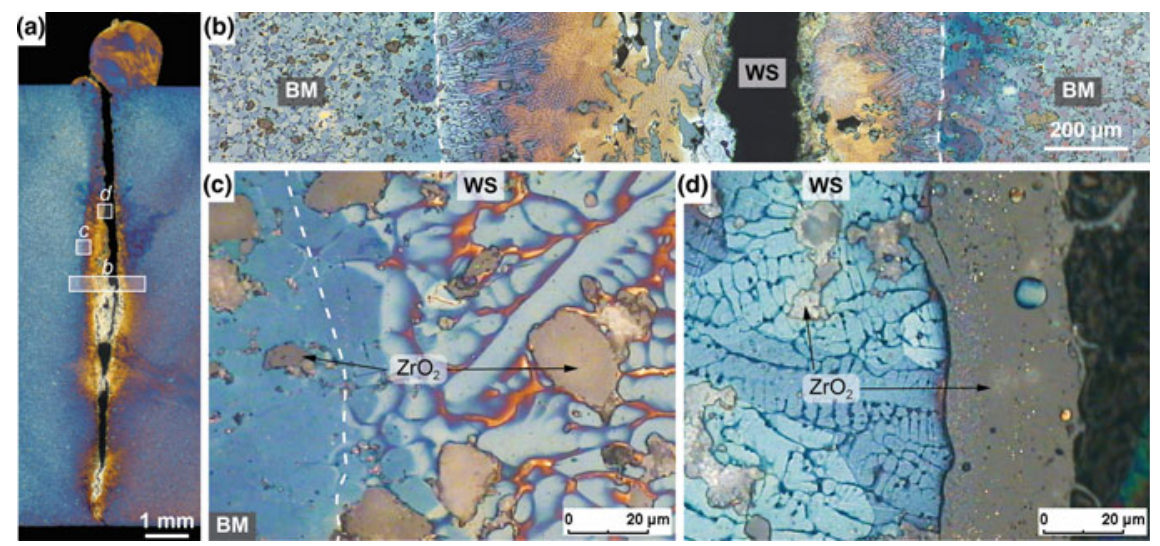

Fig. 10.11 Light optical micrographs of a respresentative welding seam $\left(I_{\mathrm{B}}=15 \mathrm{~mA}, v_{\mathrm{s}}=5 \mathrm{~mm} / \mathrm{s}\right)$. a Macroscopic view; $\mathbf{b}$ enlarged section of the joint; $\mathbf{c}$ transition zone between BM and WS; $\mathbf{d}$ transition zone between WS and the cavity. Dashed lines mark the melting line 
Irrespective of the parameter set selected, the formation of a cavity occurred in the centerline of the weld which extended across the entire weld depth. During the welding process, strong spatter formation occurred, resulting from the explosive evaporation of the ceramic particles. As can be seen in Fig. 10.11c, individual MgPSZ particles appeared to remain unchanged in the weld. Other ceramic particles were partially melted and deposited at the edge of the cavity (cf. Fig. 10.11d).

Parameter studies showed that the cavity could not be avoided. Its size could be minimized by the following measures:

1. reduction of welding speed (down to $5 \mathrm{~mm} / \mathrm{s}$ )

2. increase of oscillation width up to $1.5 \mathrm{~mm}$

3. shift of the beam focus below the sheet surface.

Investigations on welds without keyhole showed that the ceramic particles only tend to evaporate when the deep welding effect occurs. With wide melting baths and low penetration depths, it was possible to produce defect-free remelting paths. The ceramic particles floated on top of the melt and formed a firmly adhering, cracked top layer during cooling. The residual melt was almost free of Mg-PSZ. Other process specific optimizations, such as a pulsed beam current and the use of several concurrent welding spots (Multi-Spot-technique) had no significant influence on the formation of cavities.

Concludingly, deep penetration welding of the similar joints with particlereinforced composite materials was not feasible. In the following, two alternative joining processes are presented: On the one hand, a welding partner of the joint was replaced by a conventional steel (Sect. 10.3). On the other hand, a soldering process with the electron beam was implemented in order to dispense with the deep welding effect (Sect. 10.4).

\subsection{Electron Beam Welding of Dissimilar Joints with TWIP-Matrix Composites}

\subsubsection{Typical Microstructure of the Welded Zone}

To investigate the influence of the ceramic particles on the welding behavior of the MMC, dissimilar joints between a TWIP matrix composite and a particle-free stainless steel (AISI 304) were produced. In order to minimize the influence of the chemical composition, a stainless steel was selected which is chemically very similar to the matrix of the composite material due to its $\mathrm{C}, \mathrm{Cr}, \mathrm{Mn}$ and $\mathrm{Ni}$ content. In order to describe the quality of the welding seams, a catalog of criteria was used based on DINEN ISO 13919-1. The main defects observed were porosity, underfill and lack of fusion. Based on the criteria shown in Table 10.6, the welds were classified into evaluation groups (EG) ranging from ' $\mathrm{B}$ ' (best weld quality) to ' $\mathrm{D}$ ' (worst weld quality). 
Table 10.6 Criteria for categorization of welding seams into evaluation groups (EG) according to DINEN ISO 13919-1. $\mathrm{f}_{P}$ : area of cavities, $\mathrm{h}^{*}$ : underfill, LoF: dimension of lack of fusion, $\mathrm{t}$ : sheet thickness

\begin{tabular}{l|l|l|l}
\hline EG & $\mathrm{f}_{P}$ & $\mathrm{~h}^{*}$ & LoF \\
\hline B & $\leq 0.7$ & $\leq 0.1 \mathrm{t}$ & n.p. \\
\hline $\mathrm{C}$ & $\leq 2$ & $\leq 0.2 \mathrm{t}$ & n.p. \\
\hline $\mathrm{D}$ & $\leq 6$ & $\leq 0.3 \mathrm{t}$ & $\leq 0.25 \mathrm{t}$ \\
\hline
\end{tabular}

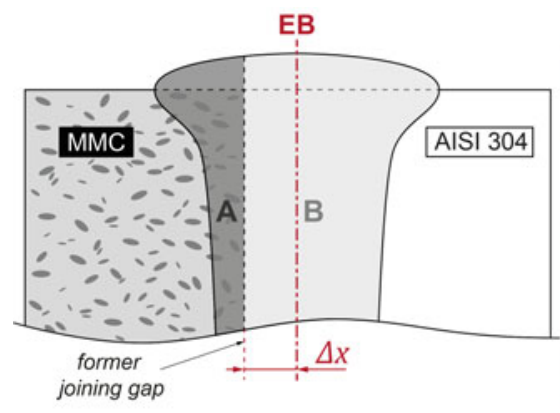

(a)

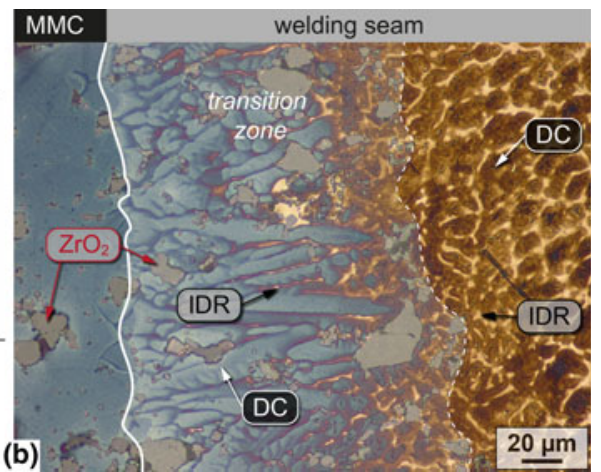

(b)

Fig. 10.12 a Schematic illustration for measuring the beam displacement and calculating the level of dilution $(D)$. b Representative section of the transition zone (TZ) between the TWIP MMC base material and the welding seam [15]. $I_{\mathrm{B}}=45 \mathrm{~mA}, v_{\mathrm{s}}=15 \mathrm{~mm} / \mathrm{s}, \Delta x=0.4 \mathrm{~mm}$

To obtain a defect-free weld, the beam offset $\Delta x$ had to be shifted relative to the particle-reinforced material (Fig. 10.12a). The level of dilution (D) was used as a measure of the amount of Mg-PSZ introduced into the weld pool (Fig. 10.12a).

Figure $10.12 \mathrm{~b}$ shows the typical microstructure of the welded samples with a beam offset $\Delta x=0.4 \mathrm{~mm}$. The fusion zone consisted of the two base materials (TWIP MgPSZ and steel AISI 304) and the welding seam, which could further be divided into two separate regions. Firstly, on the right of Fig. 10.12b, typical dendritic structures were present with brown-colored dendrite cores (DC) (cf. Suutala et al. [48]). This was the area where the steel AISI 304 was molten. Due to the primary ferritic solidification of the steel AISI 304, the ferrite was transformed into secondary austenite during cooling. Secondly, a TZ was present between the MMC material and the welding seam. In this TZ, Mg-PSZ particles were embedded within dendritic structures with a blue etching color. This coloring was due to the primary austenitic solidification of the TWIP matrix material [14]. Previous investigations have shown that the Mg-PSZ is introduced into the welding seam by the electron beam welding process, where it is agglomerated, melted and partially evaporated. This evaporation process leads to the formation of a mixture of oxides of zirconium and magnesium, which can accumulate during welding in cavities or during braze-welding in the joining gap [14]. As Fig. 10.12b shows, the particles in the welding seam and in the base 
metal possessed approximately the same dimensions. It was therefore assumed that some Mg-PSZ particles could have been introduced into the melt pool. A current field of interest is the manner in which the Mg-PSZ particles interact with the melt, the electron beam and the keyhole.

\subsubsection{Influence of Beam Parameters on the Weld Quality}

During the welding experiments without beam displacement $(\Delta x=0 \mathrm{~mm})$, the molten metal was periodically ejected (similar to the humping effect). This led to material loss and the formation of cavities (Fig. 10.13a) in the welding seam, which is known from the similar welding joints (Sect. 10.2.7).

With increasing beam displacement (up to $0.3 \mathrm{~mm}$ ), material separations along the entire weld length, even reaching the weld face were observed. Moreover, pronounced cavity formation was visible (Fig. 10.13b). From a beam offset of $0.4 \mathrm{~mm}$ (Fig. 10.13c), the typical smoothly scaled upper bead and a microscopically flawless welding seam were obtained. Occasionally, the welding seam was widened, though material separation did not occur. In summary, the welding quality improved with decreasing amounts of Mg-PSZ within the weld pool.

An underfill was evident at a beam offset of $0.4 \mathrm{~mm}$. Despite having the same bevel geometries, higher beam offsets $(0.5-0.6 \mathrm{~mm})$ did not result in underfill, but produced joints with the same scaling of upper beads (Fig. 10.13d). In order to counteract the underfill, tests were carried out without machining a bevel on the samples, with these samples exhibiting a general reduction and, partly, a complete prevention of seam
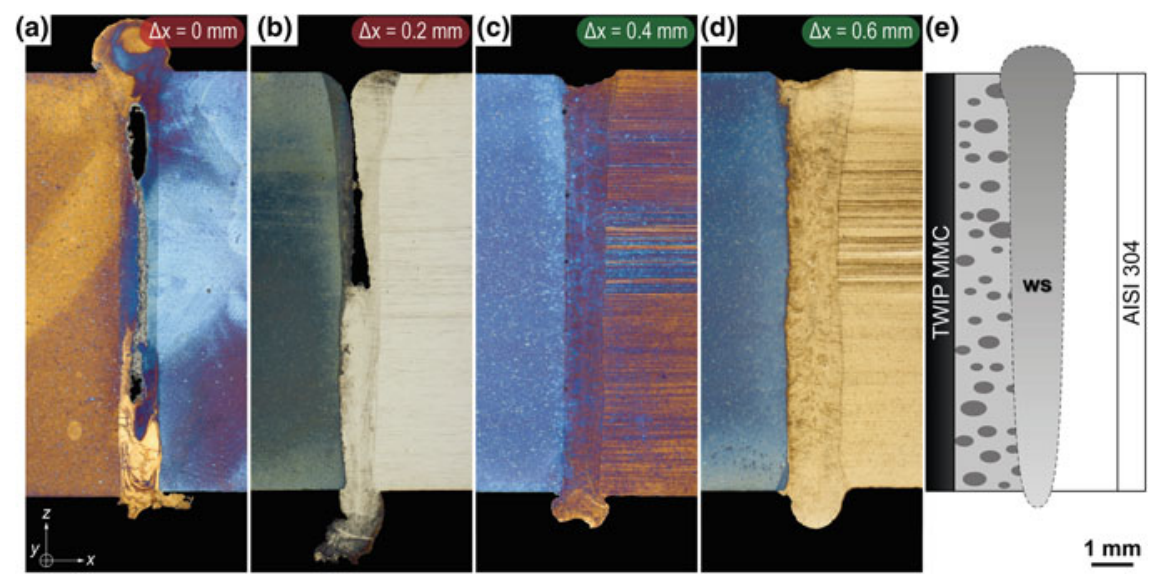

Fig. 10.13 Influence of the beam offset $\Delta x$ on the weld quality (red: EG $<$ 'D', green: EG better than ' $\mathrm{D}$ '); a-d light optical cross sections, e schematic position of the welded materials. Beam parameters: $I_{\mathrm{B}}=45 \mathrm{~mA}, v_{\mathrm{s}}=15 \mathrm{~mm} / \mathrm{s}[15]$ 


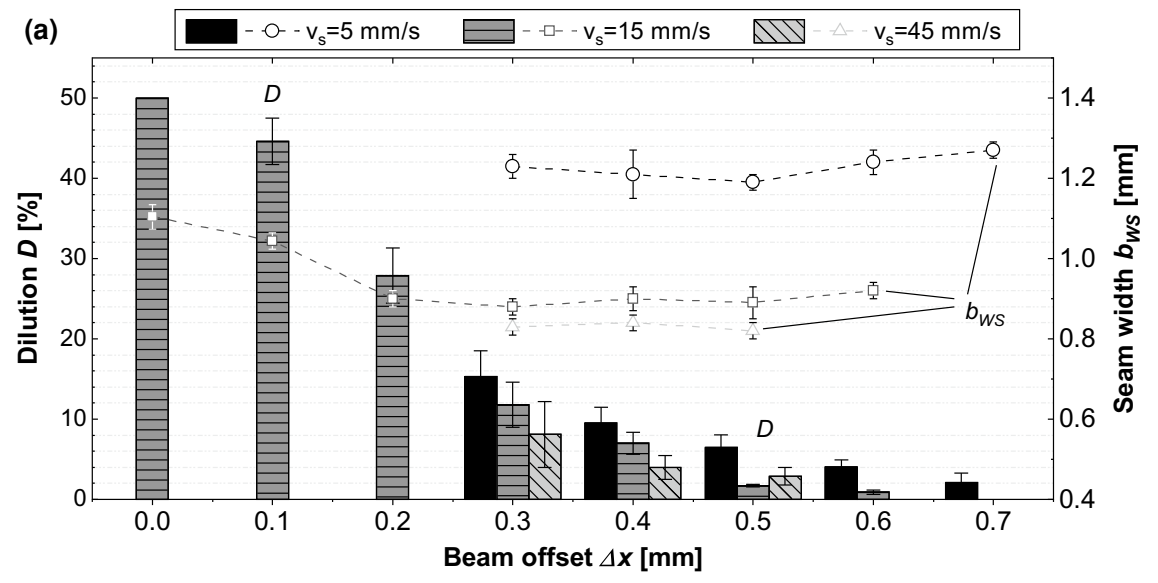

(b)
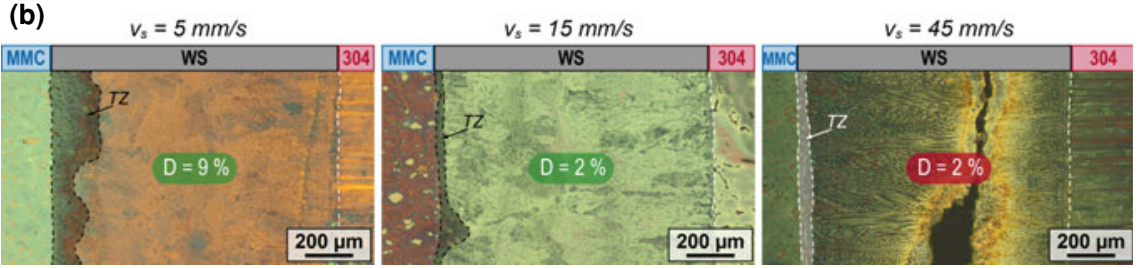

Fig. 10.14 a Resulting level of dilution (shown in bars, left axis) for different welding speeds as a function of the beam offset used. Datapoints mark the corresponding seam width (right axis). b Influence of the welding speed $v_{\mathrm{s}}$ and the level of dilution $D$ on the weld quality with respect to the area of the transition zone (TZ) for $\Delta x=0.5 \mathrm{~mm} . v_{\mathrm{s}}=5 \mathrm{~mm} / \mathrm{s}: I_{\mathrm{B}}=30 \mathrm{~mA}, \mathrm{EG}={ }^{\text {'C }}, v_{\mathrm{s}}=15 \mathrm{~mm} / \mathrm{s}$ : $I_{\mathrm{B}}=45 \mathrm{~mA}, \mathrm{EG}={ }^{\text {'D' }}, v_{\mathrm{s}}=45 \mathrm{~mm} / \mathrm{s}: I_{\mathrm{B}}=110 \mathrm{~mA}, \mathrm{EG}<$ 'D' [15]

concavity. Further examinations were then carried out with a beam offset of $0.4 \mathrm{~mm}$, and did not exhibit any underfill. For all tests without bevels, an upper bead was produced that was free of macroscopic faults. Even without a bevel, the welding gap could be located easily with the monitoring system of the EB facility.

The experiments had shown that the beam displacement was associated with characteristic defects in the welding seam. With the level of dilution $(D)$, there was an additional characteristic value which acted as a measure for the ingress of the Mg-PSZ particles and the corresponding width of the mixing zone. In Fig. 10.14a, the degrees of mixing for different welding speeds $(5-45 \mathrm{~mm} / \mathrm{s})$ are plotted with the corresponding welding seam widths as a function of the beam offset used. As expected, the level of dilution decreased with increasing beam offset regardless of the welding speed. The defect-free welds with a beam offset of $0.4-0.6 \mathrm{~mm}$ corresponded to an ingress of $<10 \%$ (Fig. 10.14a). All samples with higher dilution exhibited pores, underfills or other significant defects. The standard deviations determined were also the smallest in the offset range for samples without defects $(0.4-0.6 \mathrm{~mm})$ and increased with decreasing beam offset. Consequently, the process stability increased with increasing beam displacement. 
Based on the results of welding experiments at $15 \mathrm{~mm} / \mathrm{s}$, it could be deduced that starting from $\Delta x=0 \mathrm{~mm}$, the welding seam width decreased with increasing beam offset up to a beam offset of $0.2 \mathrm{~mm}$. This was due to the significantly lower thermal conductivity of the TWIP MMC compared to the austenitic AISI304 steel, which led to heat accumulation and, thus, to seam broadening. Above a beam offset of $0.3 \mathrm{~mm}$ and with less than $28 \%$ dilution, the welding seam width remained approximately constant, which was due to the decreasing influence of TWIP MMC material. In addition, it was shown that there was no significant change in welding seam width for welding speeds of $15-45 \mathrm{~mm} / \mathrm{s}$. On the other hand, welds with $5 \mathrm{~mm} / \mathrm{s}$ exhibited an increase in welding seam width of $\approx 35 \%$ compared to welds produced at $15 \mathrm{~mm} / \mathrm{s}$. The reason for this was the limited sample volume, which was discussed in Sect. 10.2.6.1. Regardless of the set level of dilution, all welds carried out with a welding speed of $45 \mathrm{~mm} / \mathrm{s}$ had significant defects. The micrographs in Fig. 10.14b show that despite similar levels of dilution, there were significant differences in welding quality. The ingress of the Mg-PSZ particles was therefore not the only factor that impaired the weldability of TWIP Mg-PSZ. It became clear that despite similar energy inputs per unit length, pore-containing seams were produced at welding speeds of $45 \mathrm{~mm} / \mathrm{s}$, while pore-free joints could be welded at $15 \mathrm{~mm} / \mathrm{s}$. At the same time, a higher energy input per unit length also led to an improvement in the quality of the welding seam. Therefore, it was not possible to identify any clear tendencies for the evaluation of the welding seam quality from the selected value of $E$. However, the influence of the welding speed on the quality of the welding seam was proven in this work. In contrast to the work of Chen et al. [10], improvement of the weld quality with increasing welding speed could not be found for the TWIP MMC used.

Thus, in the case of a very large beam offset $(\Delta x=0.6 \mathrm{~mm})$, it was possible to change the seam geometry by lowering the welding speed to $v_{\mathrm{s}}=5 \mathrm{~mm} / \mathrm{s}$ in such a way that almost parallel edges of the seam were created. This prevented connection faults in the root position area. Tests were carried out to select the optimum welding beam current at small beam offsets $(\Delta x=0.4 \mathrm{~mm})$ and correspondingly high entries of $\mathrm{Mg}$ PSZ ( $D \approx 12 \%$ ) into the weld pool. It was observed that the minimal beam currents necessary for full-penetration welding often led to pore formation and connection errors in the root position. Raising the beam current by $\approx 20 \%$ led to better melt degassing, on the one hand, and to more parallel weld edges on the other hand, which positively influenced both the connection quality and the melt degassing. However, the welding seam could only be classified as $E G=$ ' $D$ ' due to the presence of underfill.

Further tests on the influence of the focal plane position on the seam quality showed that a sharp surface focus $-\left(\Delta I_{\mathrm{F}}\right)=0 \mathrm{~mA}-$ led to strong shrinkage, underfill, and a scaled seam surface (cf. Fig. 10.15b). It should be noted that all experiments were carried out with a beam offset of $0.4 \mathrm{~mm}$, i.e. the TWIP MMC was molten and cavity formation occured, which is associated with the ingress of Mg-PSZ to the weld pool. The formation of cavities could be prevented with a shift of the focal plane over the top of the sheet metal $\left(\Delta I_{\mathrm{F}}=5 \mathrm{~mA}\right)$, but the underfill increased drastically (Fig. 10.15a). A defocus of $\Delta I_{\mathrm{F}}=-5 \mathrm{~mA}$ below the sheet surface, on the other hand, 


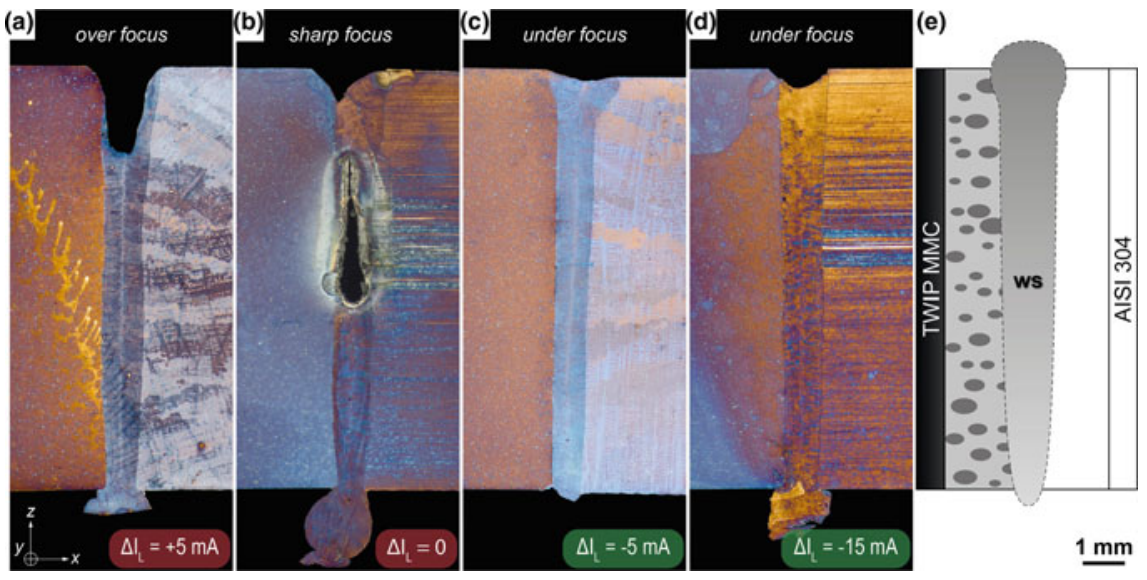

Fig. 10.15 Influence of the focal position of the EB on the weld quality (red: EG $<$ 'D', green: EG better than 'D'), according to the lens current used; a-d light optical cross sections; $\mathbf{e}$ schematic position of the welded materials. Beam parameters: $I_{\mathrm{B}}=45 \mathrm{~mA}, v_{\mathrm{s}}=15 \mathrm{~mm} / \mathrm{s}, \Delta x=0.4 \mathrm{~mm}$ [15]

produced a pore-free welding seam with a finely scaled bead surface and without underfill (Fig. 10.15c). With further defocusing of the beam, however, the porosity was unaffected (pore size $<80 \mu \mathrm{m}$ ), but the underfill was increased (see Fig. 10.15d). This was attributed to the dependence of process stability on the stability of the keyhole. With a sharp focus on the surface, the capillary was not opened wide enough, and was quite susceptible to the ingress of ceramic particles. A larger opening of the steam channel resulted in better degassing and, therefore, better welding results. Tests on welded aluminum joints by Ahn et al. showed similar tendencies [2].

\subsubsection{Verification of Welding Defects}

For the ultrasonic immersion tests, the entire welding seam was scanned in the longitudinal direction (see Fig. 10.3). The aim of the non-destructive testing was to detect welding defects, such as a lack of fusion or cavities. In addition to the determination of the defect position in the y-z direction, the flaw depth was determined while taking into consideration the longitudinal wave velocity of the AISI 304 steel. The size of the Mg-PSZ particles was below the resolution limit, which meant that no negative influence could be detected using either the ultrasonic immersion test or $\mathrm{X}$-ray inspection.

Figure 10.16a1 shows the D-scan of a welding seam with pores and lack of fusion for a sample with $\mathrm{EG}<$ 'D'. With respect to the D-scan, it was assumed that a connection was only present at the edge of the sample. This was confirmed by the light optical micrographs in Fig. 10.16a3, a4. The flaw depth information indicated a planar defect (lack of fusion) at a depth of $\approx 5.5-6.5 \mathrm{~mm}$ (indicated by the light 

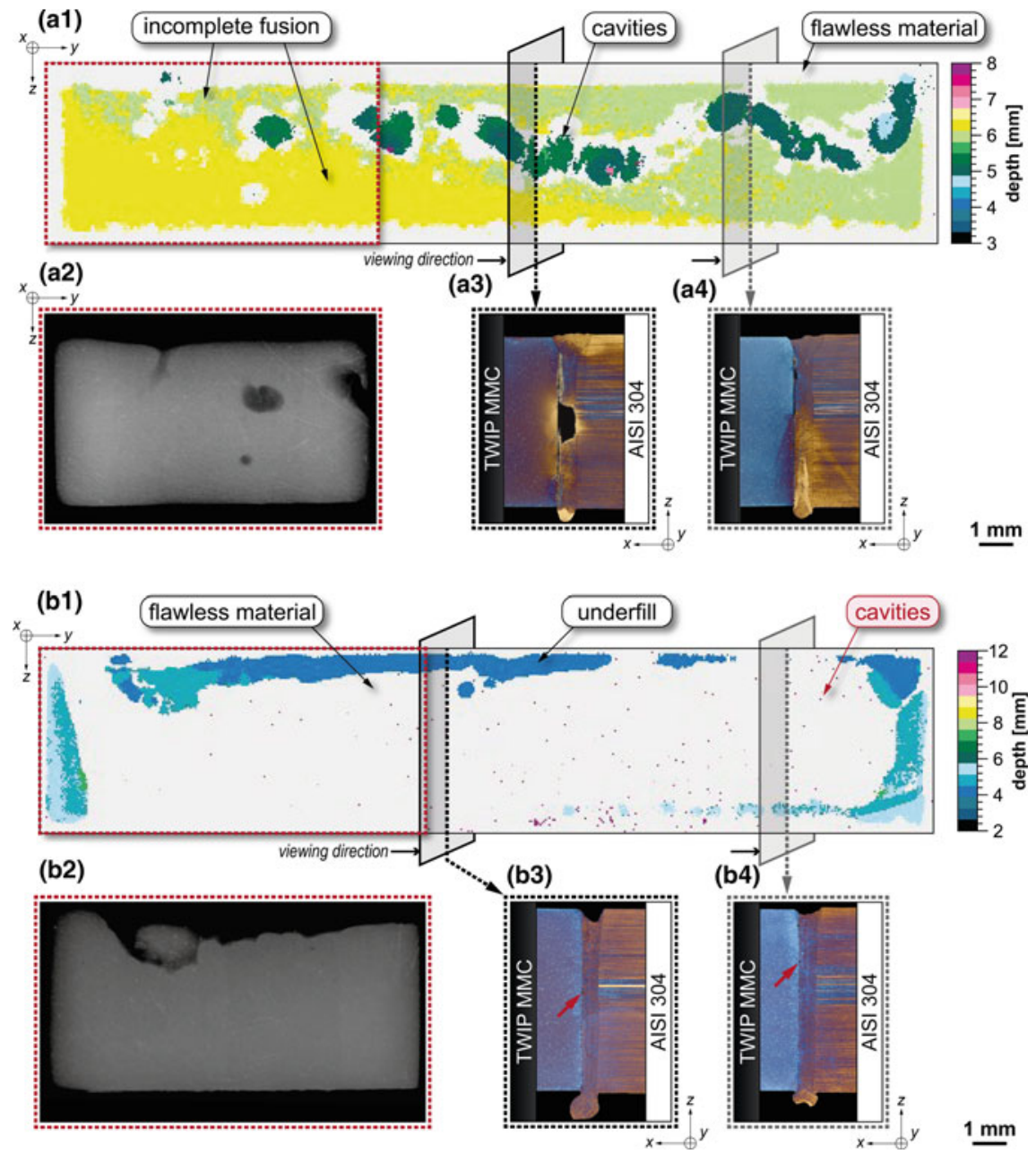

Fig. 10.16 a Testing results of sample with $\mathrm{EG}=$ 'C', beam parameters: $I_{\mathrm{B}}=46 \mathrm{~mA}, v_{\mathrm{S}}=15 \mathrm{~mm} / \mathrm{s}$, $\Delta x=0.6 \mathrm{~mm}$; b testing results of sample with $\mathrm{EG}<$ 'D', beam parameters: $I_{\mathrm{B}}=45 \mathrm{~mA}$, $v_{\mathrm{s}}=15 \mathrm{~mm} / \mathrm{s}, \Delta x=0.4 \mathrm{~mm} .1$ Ultrasonic immersion results with the depth information of the signal (testing axis: $\mathrm{x}$ ). $2 \mathrm{X}$-ray image of the marked section (red dashes, testing axis: $\mathrm{x}$ ). 3 , 4 Cross sections at positions marked in 1 (dashed arrows) [15]

green to yellow color), which was assigned to the TWIP MMC. Small deviations in the measured depths of planar defects resulted from deviations in plane-parallelism in the processing of samples for the ultrasonic immersion testing. The areas with the dark green color in Fig. 10.16a1 indicated weld defects-where ultrasonic waves are reflected earlier than from planar defects. Taking into account the shape of the defect, which extended into the welding seam, the occurrence of pores in the sample was assumed. The light optical micrograph in Fig. 10.16a3 supports this assumption. 
Indeed, the formation of worm-holes was assumed due to the irregular arrangement of the pores in the longitudinal direction of the welding seam. Worm-holes are formed by rising gases that remain in the welding seam. In addition to the verification of the investigation via ultrasonic immersion testing, X-ray inspection was applied for a selected area of the sample (see Fig. 10.16a2). Volume defects such as pores were located within the X-ray image, which concurred with the D-scan carried out by means of ultrasonic immersion testing and the light optical micrographs. However, no information was available about the flaw depth. Furthermore, a lack of fusion was not detected via X-ray inspection.

Figure 10.16b1 shows the D-scan of a welding seam for a sample with $E G=$ 'C'. The welding seam exhibited an almost flawless connection between the joining partners. However, an underfill and pores at the micrometer scale were derived from the D-scan. Furthermore, due to slope-in and slope-out effects, a defective connection was observed at the edge of the sample. The existence of pores at the micrometer scale was verified by light optical micrographs (see red arrows in Fig. 10.16b3 and Fig. 10.16b4). Thus, the detection limit for the pore diameter was 90-100 $\mu \mathrm{m}$. According to DINEN ISO 13919-1, individual pores with this dimension can be tolerated within welding seams if no special type of load is defined. Hence, an adequate resolution limit existed to detect all significant defects via ultrasonic immersion testing. By X-ray inspection, both the underfill and the microporosity were determined to a resolution limit of $25 \mu \mathrm{m}$ (see Fig. 10.16b2).

\subsubsection{Mechanical Characterization}

Investigations were carried out to determine whether the welding process was associated with a change in hardness from the base material (TWIP) to the welding seam and, in particular, to the transition zone (cf. Fig. 10.17). In the transition zone, a drop in Martens hardness of about $300 \mathrm{MPa}$ was detected compared to the remaining welding seam (Fig. 10.17). These differences were due to the different solidification modes from the transition zone (AF mode) as well as the welding seam (FA mode) and the associated $\delta$-ferrite contents.

Furthermore, the presence of Mg-PSZ particles within the base material led to higher measured hardness values. On the other hand, the absence of those particles within the transition zone again led to lower measured hardness values. Due to the very similar chemical composition of both joining partners, however, no significant change in hardness was found within the measured profile. Individual areas that had a very high degree of hardness $(\approx 2600 \mathrm{MPa})$ in the TWIP base material were interpreted as Mg-PSZ particles.

Figure 10.18 shows the mechanical properties of the tensile test for a comparative characterization of the welded joints with different levels of dilution. With respect to the experiments at $v_{\mathrm{s}}=15 \mathrm{~mm} / \mathrm{s}$, it became clear that the highest ultimate tensile strengths were present at $D$ of $12 \%(\Delta x=0.3 \mathrm{~mm})$. The median tensile strengths achieved were at $545 \mathrm{MPa}$ with an uniform strain of $8.2 \%$. However, these welding 


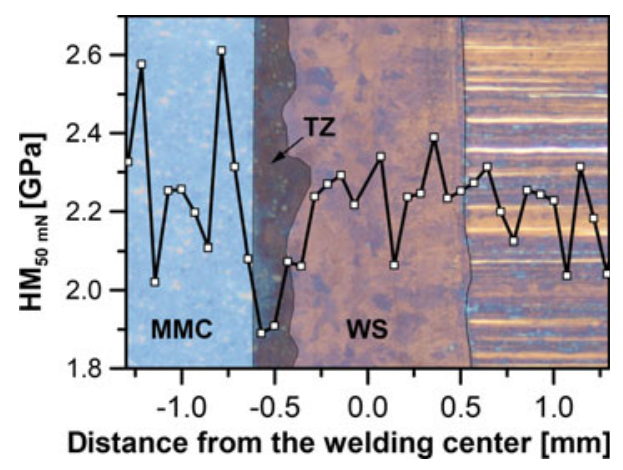

Fig. 10.17 Microhardness profile across the welded materials and the fusion zone. Beam parameters: $I_{\mathrm{B}}=30 \mathrm{~mA}, v_{\mathrm{s}}=5 \mathrm{~mm} / \mathrm{s}, \Delta x=0.5 \mathrm{~mm}, D \approx 9 \%[15]$
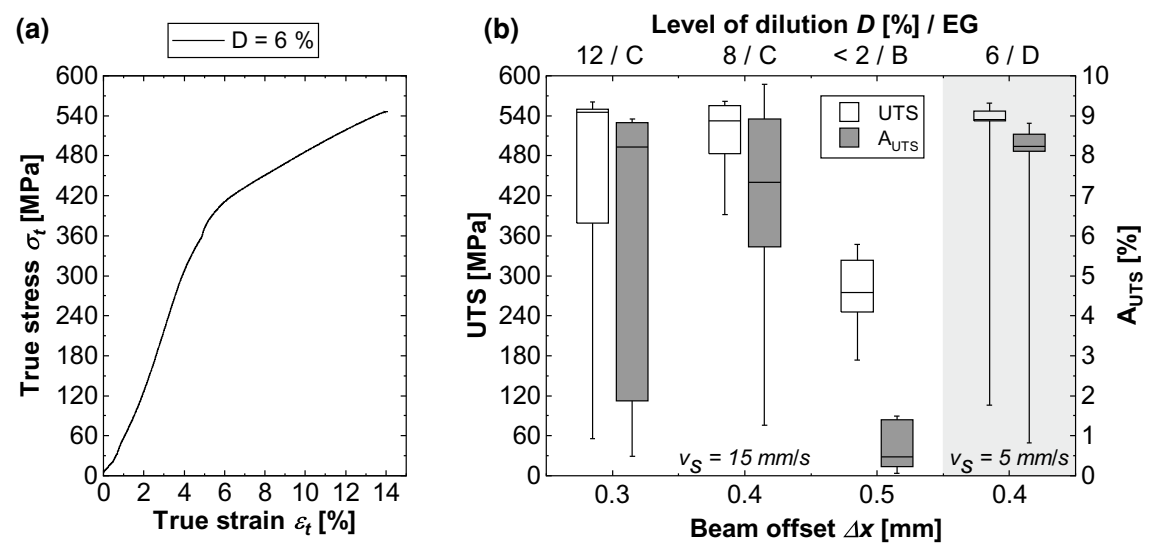

Fig. 10.18 Influence of the level of dilution and the beam offset on the mechanical properties. a Representative stress-strain curve for $D=6 \%$; b boxplot of the ultimate tensile strength and the uniform strain $\left(A_{\mathrm{U}}\right)$ as a function of $\Delta x$ and $D[15]$

seams were categorized as $\mathrm{EG}={ }^{\text {' }} \mathrm{C}$ ' due to the very high porosity. Therefore, failure took place within the welding seam with a very high amount of scatter. At lower degrees of mixing $(D=8 \%, \Delta x=0.4 \mathrm{~mm})$, the joints could also be evaluated as $\mathrm{EG}=$ ' $\mathrm{C}$ ', but exhibited slightly lower strength and strain values (UTS $=532 \mathrm{MPa}$, $A_{\text {UTS }}=7.3 \%$, both medians). Individual large pores within the welding seam led to failure of the samples. Joints that exhibited hardly any melting of the base metal $(D<2 \%, \Delta x=0.5 \mathrm{~mm})$ exhibited the worst mechanical properties. Failure took place alongside the fusion line even at low stress levels $\left(\mathrm{UTS}_{\text {med. }}=275 \mathrm{MPa}\right)$. The samples broke in an almost brittle manner with hardly any measurable elongation $\left(A_{\mathrm{UTS}}\right.$, med. $\left.=0.5 \%\right)$.

Contrary to these findings, the joints were free of pores, exhibited neither underfill nor lack of fusion and were evaluated as EG = 'B' according to DINEN ISO 13919-1. 
Halbauer et al. [13] attribute the low mechanical properties at very high beam offsets to the formation of an oxide-containing layer at the fusion line, which prevents complete joining of the two welding materials. Since the occurrence of planar defects and, in particular, non-wettable oxide layers are not covered by DINEN ISO 13919-1, the mechanical properties of the welding joints could not be derived solely from the evaluation group. Instead, further investigations were required to determine, in particular, the quality of connectivity. The investigation of this bonding strength on the microscopic scale will be discussed in detail in a future publication. Improvement of the mechanical properties was achieved by using a lower welding speed $\left(v_{\mathrm{s}}=5 \mathrm{~mm} / \mathrm{s}\right)$ and setting a low dilution level of the TWIP MMC $(D=6 \%, \Delta x=0.4 \mathrm{~mm})$. In this way, tensile strengths of $535 \mathrm{MPa}$ (med.) were achieved with a uniform elongation of $8.2 \%$ and with minimum scatter of the tensile strength. Since no significant porosity was found, rupture of the samples took place within the base material of the TWIP MMC. This was made possible by the significantly longer interaction time between the EB and the melt, which led to better degassing and calming of the melt. According to DINEN ISO 13919-1, these welds had to be categorized as EG = 'D' due to the presence of underfill. However, these defects were not relevant for the mechanical properties due to the high ductility of the steel AISI 304 within the welding seam.

\subsection{Electron Beam Brazing of TWIP-Matrix Composites}

\subsubsection{Macroscopic Phenomena}

It was investigated, how the energy distribution $P(y)$ of the electron beam as a function of the position can influence the temperature distribution at the sample surface (Fig. 10.19) during the brazing process. First, heating experiments without filler material were carried out with a constant energy across the EB field width (Fig. 10.19a). As expected, the temperature exhibited a maximum at the center of the separate energy transfer fields and a sharp temperature gradient towards the edges was present (Fig. 10.19c). Accordingly, this temperature distribution led to partial melting in the middle of the EB interaction field and high distortion in x-direction.

Second, $P(y)$ was adjusted according to (10.1) with $P_{\min }=0.8$ (Fig. 10.19b). Due to the variation of energy input, the resulting temperature distribution was homogeneous in y-direction, which allowed the filler to melt more homogeneous, prevented partial surface melting and reduced the distortion of the samples significantly (Fig. 10.19d). If $P_{\min }$ was further decreased, more energy was introduced to the edges of the samples, which again led to inhomogeneous temperature distributions and partial melting of the sample surface. All samples discussed in the following were brazed with this adjustment of the energy distribution.

Figure 10.20a illustrates the evolution of the filler gap $\left(h_{\mathrm{f}}\right)$ after brazing and is representative for the investigated samples in the longitudinal section (y-direction). The gap width after brazing was much smaller than the initial gap width $\left(h_{\mathrm{f} \text {,init }}\right)$ (i.e. 


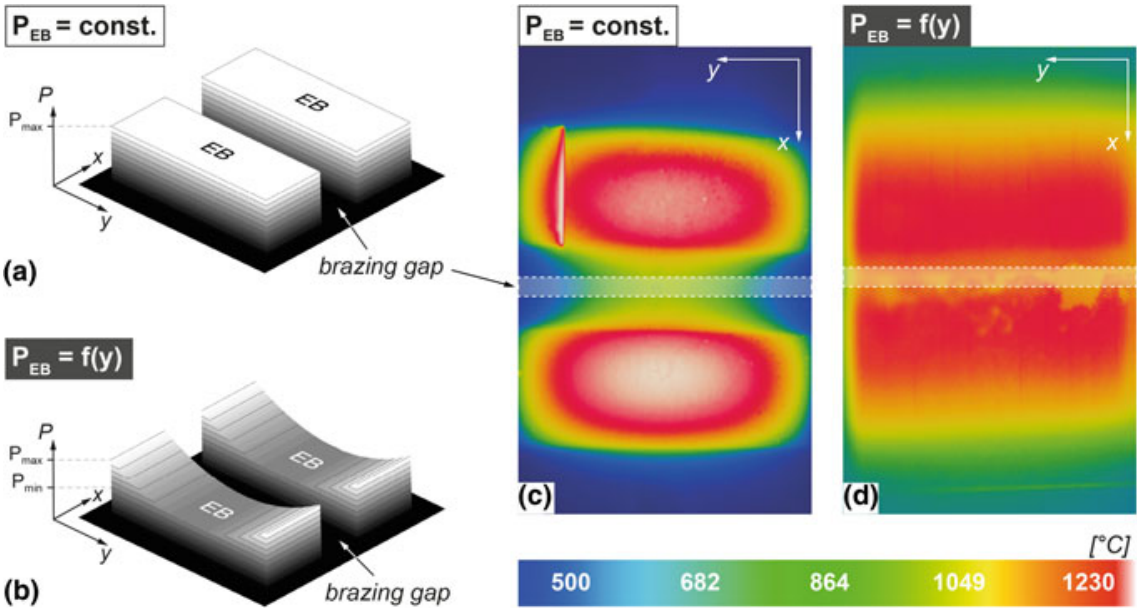

Fig. 10.19 Influence of the energy distribution on the temperature distribution at the sample surface during brazing. a, b Schematic illustrations of the set beam interaction field; c, $\mathbf{d}$ resulting temperature distribution measured with a thermographic camera (adapted from [16])

(a)

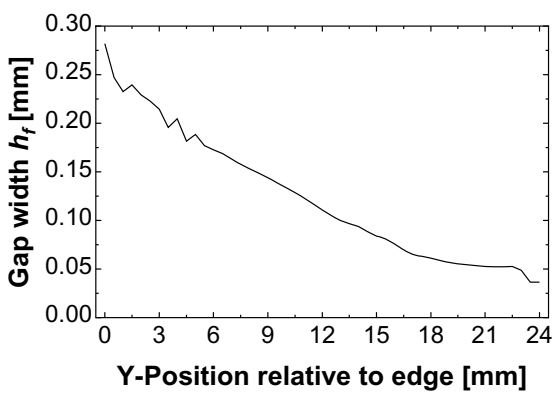

(b)

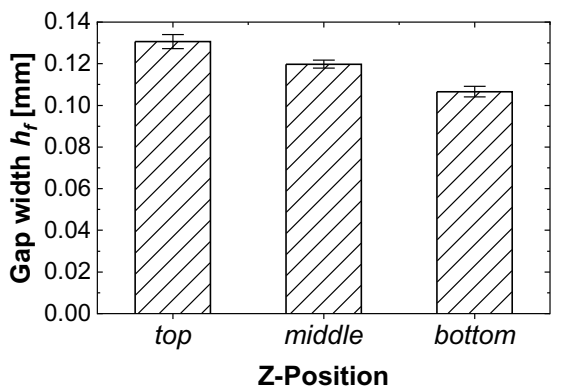

Fig. 10.20 Evolution of the filler gap width $\left(h_{\mathrm{f}}\right)$ after brazing a depending on the distance from the sample edge (longitudinal section); $\mathbf{b}$ depending on the z-position of the measurement (crosssection). Initial gap $=800 \mu \mathrm{m}, t_{\mathrm{H}}=67 \mathrm{~s}$ (adapted from [16])

$\left.h_{\mathrm{f}, \text { init }}=1200 \mu \mathrm{m}, h_{\mathrm{f}, \max }=300 \mu \mathrm{m}\right)$. During heating, the width of the gap decreases according to thermal expansion, since the samples are fixed within the clamping device. If the gap is too small, the clamping device is able to compensate the contact stress with an internal suspension. However, during cooling, the solidified filler material prevented the base material from retaining its original shape which clearly led to internal stresses. After brazing the resulting gap width decreased sightly from the top $(130 \pm 3 \mu \mathrm{m})$ to the bottom $(106 \pm 2 \mu \mathrm{m})$ of the samples (cf. Fig. 10.20b). Due to the high sheet thickness, the unilateral heating of the samples and the short holding time a temperature gradient of $\approx 100 \mathrm{~K}$ from the top to the bottom of the samples (z-direction) developed. However, in the authors' opinion the resulting gra- 
(a)

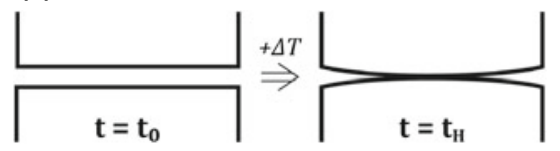

(b)

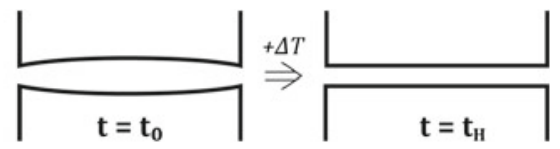

Fig. 10.21 Evolution of the filler gap geometry before $\left(t=t_{0}\right)$ and during brazing $\left(t=t_{\mathrm{H}}\right)$ due to distortion a without uniform gap, $\mathbf{b}$ with crowned gap geometry. $t_{0}=0 \mathrm{~s}$ (after [16])

(a)

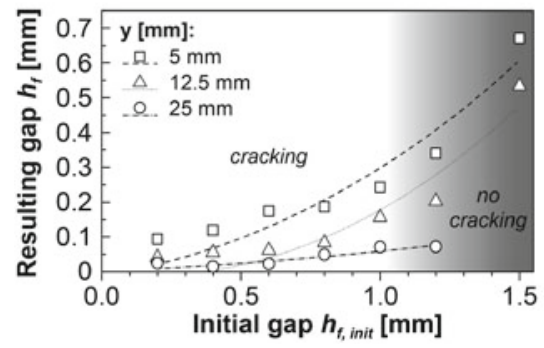

(b)

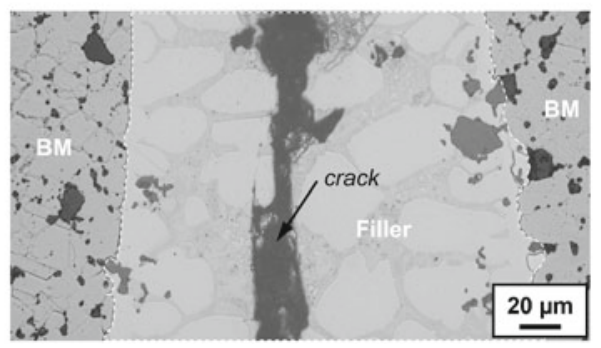

Fig. 10.22 a Gap width after brazing (resulting gap) $2 \mathrm{~mm}$ below the sheet surface as a function of the initial gap at different distances from the sample edge $\left(t_{\mathrm{H}}=52 \mathrm{~s}\right)$; b Typical crack within the center of the brazing gap (modified from [16])

dient in thermal expansion from the top to the bottom was negligible and was not the reason for the gradient of the gap width. It was more likely, that diffusion controlled mechanisms such as erosion, caused the gap to widen at the top, which is explained in detail in Sect. 10.4.2.

Though the energy field was optimized to ensure uniform temperatures across the sample, the thermal expansion exhibited a gradient from the center (high) to the edge (low) (Fig. 10.21a). This gradient could be compensated by the addition of a crowned gap geometry (Fig. 10.21b).

The gap width $h_{\mathrm{f}}$ was also influenced by the initial gap width before brazing, cf. Fig. 10.22a. As expected, the resulting gap width decreased with the decreasing initial gap. For $h_{\mathrm{f} \text {,init }}<1 \mathrm{~mm}$ the two joining partners had direct contact in the center of the gap and therefore $h_{\mathrm{f}}$ was mainly influenced by the solidification of the surrounding filler material and exhibited cracks due to insufficient feeding (cf. Fig. 10.22b). With increasing $h_{\mathrm{f} \text {,init }}(>1.2 \mathrm{~mm})$ the gap width was mainly influenced by the thermal expansion across the sample and no cracks were observed. Concludingly, a gap width $\geq 1.2 \mathrm{~mm}$ should be used for potential application. 


\subsubsection{Microscopic Characterization}

Figure 10.23 shows an exemplary cross section of the joint between the particle reinforced TWIP steel (TWIP matrix composite (TMC)) with Ni-filler and $h_{\mathrm{f} \text {,init }}=$ $1.2 \mathrm{~mm}$. From the edge to a distance of $y \approx 10 \mathrm{~mm}$ neither pores nor cracks were found. Due to the strong distortion during heating, the center of the gap exhibited solidification cracks across the whole sample height. A dendritic microstructure consisting of dendrite cores (DC) (Fig. 10.23b, light grey) and an interdendritic region (IDR) (Fig. 10.23b, dark grey) were present. Following the temperature gradient in z-direction, a transition zone was detected (Fig. 10.23c, d), which decreased in width from the top $(\approx 85 \mu \mathrm{m})$ to the bottom $(\approx 18 \mu \mathrm{m})$ of the samples. In this transition zone, particles from the base material were visible. The chemical composition of the matrix between the particles was similar to that of the filler material. Based on the investigations made, the transition zone formed as a result of a diffusion induced erosion and the formation of phases between the filler and the base material. The IDR consisted of low melting phases, exhibited a fine, lathy internal structure (Fig. 10.23b) and is believed to be an eutectic phase.

The distribution of the low melting phases was investigated by the binarization of the light optical micrographs. Independent on the base material used, the joined area consisted of $\approx 50 \%$ eutectic phases and the phases were distributed heterogeneously across the sheet thickness. If a very long holding time was applied $\left(t_{\mathrm{H}}=600 \mathrm{~s}\right)$, the
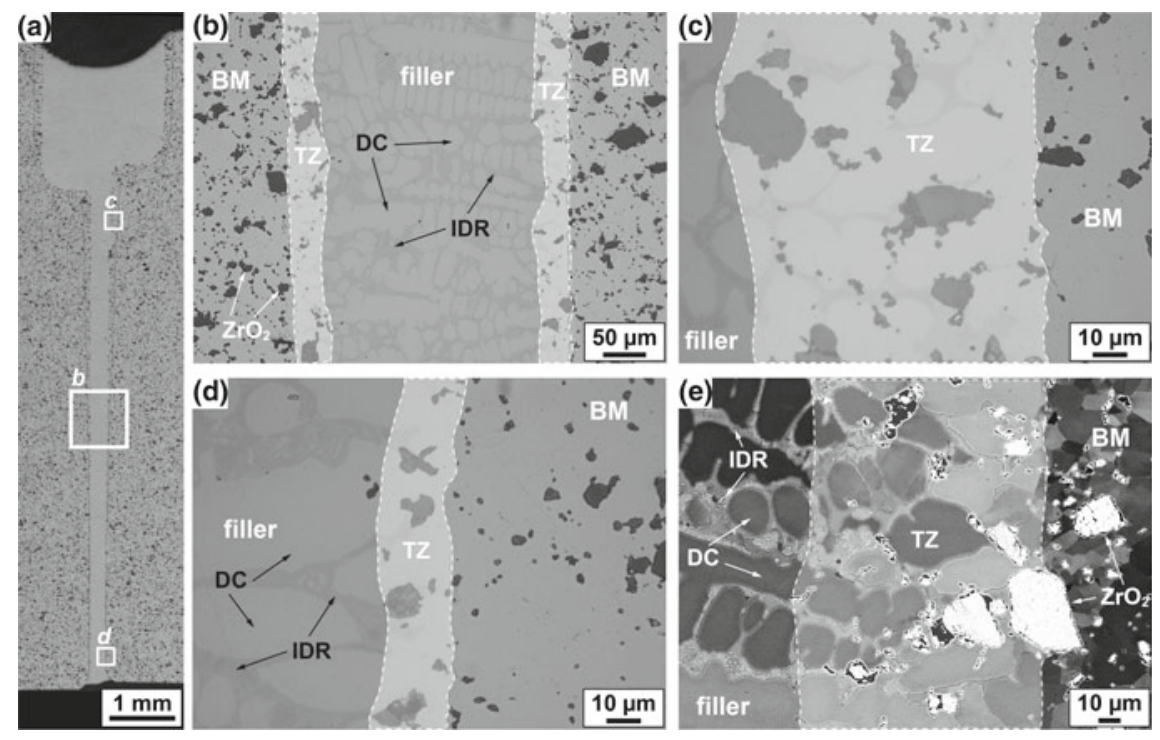

Fig. 10.23 Microstructure of the brazed samples (cross sections at $5 \mathrm{~mm}$ from the sample edge), a-d light optical investigations at different positions, e SEM image of the gap center (detail). BM: base material, TZ: transition zone, IDR: interdendritic region [16] 
content of eutectic phases could be reduced to at least $35 \%$ with a minimum of $20 \%$ at the middle of the sample height. However, due to the high amount of energy input, such long holding times have to be considered critically in terms of efficiency and economics. To minimize the content of brittle phases, either the dendritic solidification has to be enhanced drastically by applying significantly higher solidification rates or a change of the alloying system has to be considered.

The evolution of the transition zone was further analyzed by a combination of EBSD investigation with parallel energy-dispersive X-ray spectroscopy (EDS) (Fig. 10.24). The transition zone between the base material and the filler consisted of FCC dendrite cores (Fig. 10.24b) and Cr-Ni-Si intermetallic compounds with varying stoichiometry within the IDR. According to literature, these compounds are likely to occur as eutectic phases within the $\mathrm{Cr}-\mathrm{Ni}$-Si system. They are characterized by a good oxidation resistance but are also very brittle [1, 24, 47]. Also the tetragonal phase of zirconia was present, which implies, that zirconia particles would still be able to undergo a phase transformation during deformation. At the fusion line, a strong orientation relationship between the filler and the base material was present (Fig. 10.24c). Furthermore, a preferred orientation in [001]-direction was found within the dendrites, which is common for materials with a cubic microstructure.

Though the filler material was initially free of iron, significant iron contents were found within the filler after brazing. Concludingly, a diffusion of Fe from the BM into the filler had happened. As expected, the dendrite cores were also enriched with $\mathrm{Cr}$ and $\mathrm{Ni}$, since these were the main constituents of the filler material. The IDRs were enriched with $\mathrm{Si}$ due to the formation of the intermetallic phases. $\mathrm{Zr}$ was primarily found within the Mg-PSZ particles of the base material and the transition zone within the filler (Fig. 10.24e-h). It should be noted, that a strict separation between $\mathrm{Zr}$ and $\mathrm{Si}$ is not possible due to the EDS analysis method. The $\mathrm{K} \alpha$ peak of silicon and the L $\alpha$ peak of zirconium have a very similar energy level. As a result the analysis software tends to detect $\mathrm{Si}$ in regions enriched with zirconium and vice versa. Accordingly, the very high amounts of silicon within the ceramic particles (Fig. 10.24g) should not be considered as realistic. The Mg-PSZ particles were only found at a distance of $18-85 \mu \mathrm{m}$ from the fusion line and were distributed as homogeneously as in the base material. It was concluded, that the particles penetrated into the filler with a significant melt flow. This rather suggested, that an erosion process had taken place during the brazing process, which was incorporated with a chemical dissolution of the matrix and without movement of the particles. Since the erosion ensures the wettability of the base material it is a desired phenomenon and should not be avoided. Altogether, the formation of the brazing zone can be described as followed:

1. erosion of the BM by the filler and formation of a $\mathrm{Fe}-\mathrm{Cr}-\mathrm{Ni}-\mathrm{Si}$ system

2. epitactic growth of the filler onto the BM with primary FCC-solidification

3. formation of a preferred orientation in growth direction

4. enrichment of the remaining melt with $\mathrm{Si}$ and $\mathrm{Ni}$

5. formation of low melting phases/eutectics within the IDR

6. contraction of the dendrite cores during further cooling. 

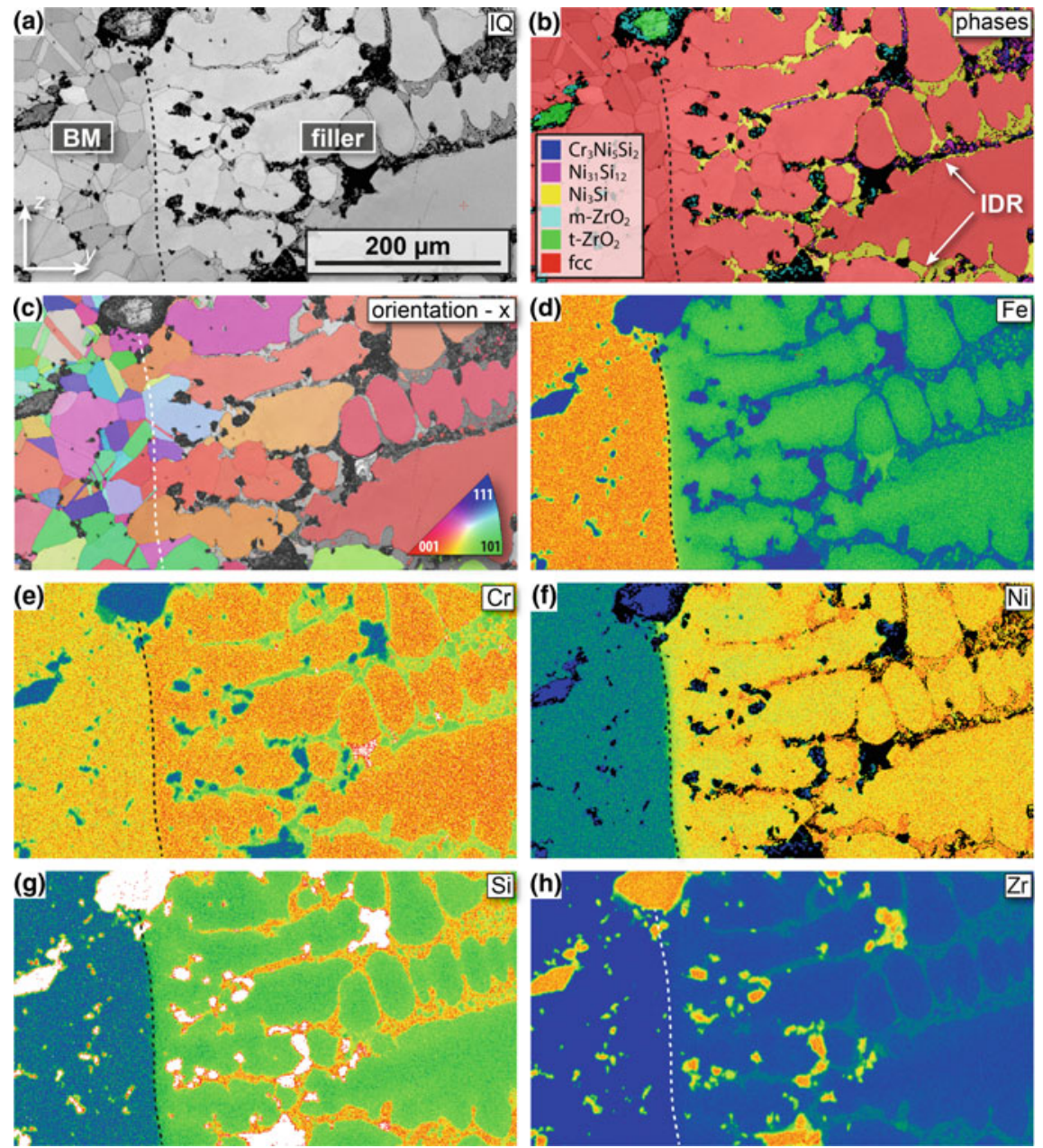

Fig. 10.24 EBSD investigation of the transition zone between BM and filler. a Image quality (IQ) map, $\mathbf{b}$ phase distribution map + IQ, $\mathbf{c}$ grain orientation in $\mathbf{x}$-direction. $\mathbf{d}-\mathbf{h}$ EDS mapping of different alloying elements as heat maps (the warmer the color, the higher the local content; black/white areas indicate data below/above the scale). Dashed lines represent the fusion line [16]

\subsubsection{Tensile Tests}

Figure 10.25 shows the results of the tensile tests with the mechanical properties UTS and elongation at rupture $\left(A_{\mathrm{R}}\right)$. Brazing joints with TMC reached up to $358 \mathrm{MPa}$ and $3.3 \%$ elongation (Fig. 10.25a). The mechanical properties can be compared to the base material only to a limited degree since the production process and chemical composition have a huge impact. When compared to braze welded flat tensile specimen (TWIP + as-cast TRIP), the UTS dropped to $\approx 62 \%$ of the base material (BM: 
(a)

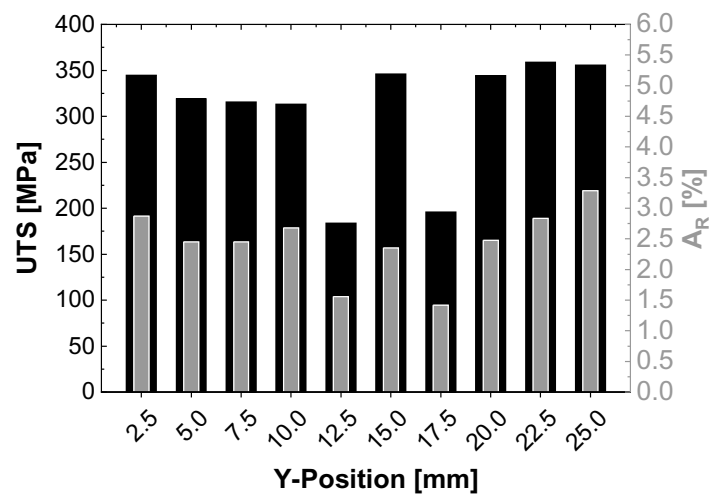

(b)

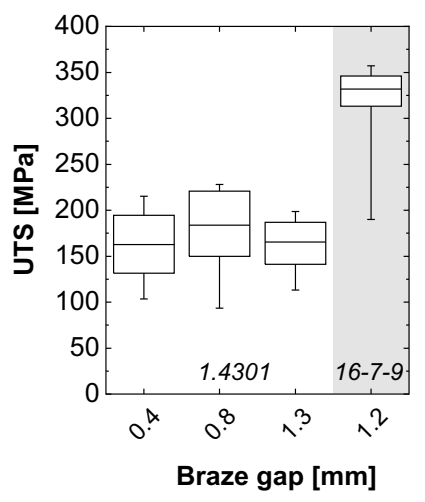

Fig. 10.25 Results of tensile tests with Ni-based filler. a UTS and $A_{\mathrm{R}}$ depending on the position of preparation (TMC, $\left.t_{\mathrm{H}}=67 \mathrm{~s}, h_{\mathrm{f}}=1200 \mu \mathrm{m}\right)$, b UTS dependent on the brazed material and the width of the initial braze gap [16]

$\mathrm{UTS}=558 \mathrm{MPa})$ and only $12 \%$ of the elongation was left $\left(\mathrm{BM}: A_{\mathrm{R}}=26 \%\right)$. These values are in good agreement with the investigations on round tensile specimen [14] (UTS $=573 \mathrm{MPa}, A_{\mathrm{R}}=29 \%$ ). Eckner et al. investigated a TRIP/TWIP steel with $6.6 \% \mathrm{Ni}$ and found a true tensile strength of $686 \mathrm{MPa}$ and $21 \%$ true strain for a SPS sintered base material. Though the samples exhibited high differences in the gap width, the mechanical properties remained nearly constant within all tested samples (Fig. 10.25a). At some positions, a sudden drop in strength and ductility was detected, which correlated with an incomplete filling of the gap due to pores or material separation.

Moreover, the gap width had an influence on the UTS of joints with steel 1.4301 and Ni-filler (Fig. 10.25b). Though the scatter decreased slightly with increasing $h_{\mathrm{f} \text {,init }}$, the strength of the braze joint was independent of the initial gap width. As a result of the higher amount of eutectic phases, joints with steel 1.4301 exhibited a significantly lower tensile strength compared to the TWIP matrix composite. The samples exhibited mostly elastic deformation and always broke within the filler material. Investigations with nano hardness measurements confirmed the existence of brittle phases within the IDR (cf. Fig. 10.26). These phases could not be avoided by the variation of the holding time and had a Martens hardness of HM $50 \mathrm{mN}=6.8$ 7.4 GPa. Due to the limitation of the minimum force and the positioning system, the separate phases within the IDR could not be investigated separately. Accordingly, the hardness is averaged across all phases of the IDR. Neither the hardness values of the IDR nor of the dendrite core were dependent on the holding time applied. With higher holding time the content of eutectica as well as the scatter of hardness decreased, due to the more homogeneous distribution of the formed phases. Since the formation of brittle phases is intensified by the formation of large dendrites within the Ni-filler, they could be minimized by decreasing the DAS value either with even shorter holding times or smaller gaps. Since shorter holding times would lead to higher heating rates, the temperature differences between the sheet surface 
Fig. 10.26 Nano hardness investigation of the filler components depending on both the holding time and filler material. DC: dendrite core, IDR: interdendritic region (adapted from [16])

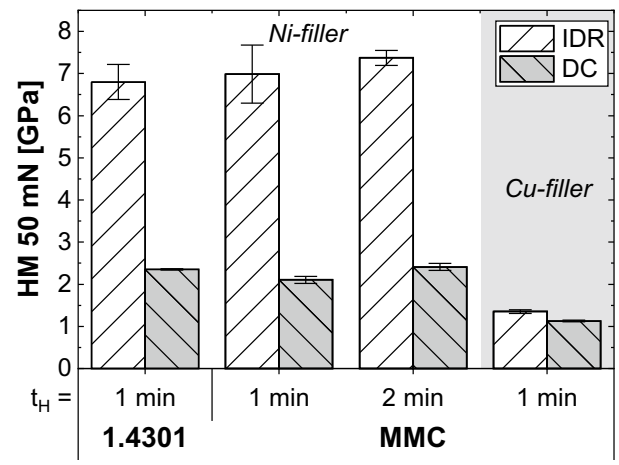

and bottom would also increase, which is not desirable for thick sheets. Smaller gaps would imply, that the joint geometry had to be changed. Two possible ways are the overlap joint, which would be beneficial for thin sheets, or the production of crowned geometries for butt joints for thick sheets. For future work, a $\mathrm{Cu}$-based filler material was pre-investigated, which has the advantage of a single phased solidification and a very low overall hardness $(1.13 \pm 0.02 \mathrm{GPa})$. Individual phases formed within the IDR were on a comparable hardness level $(1.35 \pm 0.04 \mathrm{GPa})$ which could result in significantly higher deformation of the brazing joints.

\subsection{Summary}

The contribution deals with the investigation regarding the weldability of high-alloy TRIP/TWIP materials (sheet thickness $10 \mathrm{~mm}$ ) with and without particle reinforcement. A very good weldability was found for the as-cast material without particle reinforcement. The influence of the nickel content on the welding seam geometry was only marginal. Independent of the nickel content the welding seams were free of pores and cracks and had almost parallel seam flanks.

During the welding process manganese evaporated from the base material. For welding speeds $\leq 5 \mathrm{~mm} / \mathrm{s}$, Mn loss up to $0.9 \mathrm{wt} \%$ was detected by EDS measurements. The evaporation correlated with the expansion of the molten zone at the upper bead. With both decreasing welding speed and power density the manganese evaporation increased. No significant change in the chemical composition was observed with a fully pronounced deep penetration welding effect.

The weldability of the base materials was essentially limited by humping. Similar to conventional stainless steels, increasing welding speed is accompanied by an increased tendency to hump, as shown in the literature. Steel 16-7-3 showed the highest tendency of humping. This steel was fully weldable up to a welding speed of $20 \mathrm{~mm} / \mathrm{s}$ and showed first signs of humping up to $40 \mathrm{~mm} / \mathrm{s}$. The beginning of humping for the 16-7-6 and 16-6-9 steels was at 50-60 mm/s. For welding speeds $\geq 80 \mathrm{~mm} / \mathrm{s}$, all materials were not weldable due to pronounced humping. 
The mechanical characteristics of the joints were not negatively affected by the welding process. As the nickel content increased, a decrease in strength and an increase in elongation were observed. It could be proven that the deformation mechanisms of the base material also remain effective in the weld seam. Accordingly, the weld seam also showed a very good ductility.

The particle-reinforced composite material could not be welded with keyhole. A strong melt ejection occurred and a cavity was formed in the middle of the welding zone. This cavity could be minimized, but could not be avoided by any welding parameter.

If the amount of Mg-PSZ introduced into the weld pool of dissimilar welding joints was lower than a threshold of $\approx 10 \%$ the welding seam was free of pores and cracks. The tolerable proportion of Mg-PSZ increased with decreasing welding speed. At welding speeds of 5 and $15 \mathrm{~mm} / \mathrm{s}, 9$ and 2\% Mg-PSZ were tolerable, respectively. The resulting welds were free of pores and cracks and showed mechanical properties at the level of the base material. Higher levels of dilution and velocities caused the formation of the center cavity. Furthermore, it could be shown that an underfocus of about $-5 \mathrm{~mA}$ had to be set to produce a flawless weld seam. It was assumed that this had a positive influence on the degassing behavior of the samples and was therefore necessary. Basically, it was observed that all parameters which favor degassing of the melt led to an improvement of the welding result. However, the decisive parameter for weldability was always the level of dilution. Therefore, when changing individual parameters, it may be necessary to check to what extent the weld width and thus the degree of dilution will change.

It was found that the Mg-PSZ that enters the welding zone is partially melted and tends to form clusters. Particles detected in the dendritically solidified weld metal showed no morphological changes. Therefore it was concluded that only a part of the particles interacted with the keyhole and only this part contributed to the deterioration of the material behavior. Thus, current investigations focus on the interaction of the Mg-PSZ with the electron beam.

A soldering process was carried out on butt joints consisting of a TWIP matrix composite (MMC) and a nickel-base filler material with a sheet thickness of $10 \mathrm{~mm}$. In order to keep the temperature within the soldering field as constant as possible, a polynomial energy distribution of the electron beam was used. The control of this process was realized by a temperature controlled power regulation system. Due to the geometry-related strain obstruction at the edge of the specimen, the center of the joints exhibited a lack of fusion. A complete filler connection was therefore only possible at the edge of the specimen.

Chemical erosion created a transition zone from the filler to the MMC with metallic bonding character. Thus, the nickel-base filler formed an excellent connection with the base material and a high mechanical loadability of joints was expected. Due to the high silicon content of the filler material, silicon-rich intermetallic phases were formed in the solidified solder. Due to their brittleness, the samples broke within the IDR of the filler outside of the transition zone. This lowered both the strength and the ductility of the samples. 
Acknowledgements This work was supported financially by the German Research Foundation (DFG) within the framework of the Collaborative Research Center "TRIP matrix composites" (CRC 799, project number 54473466, subproject A7). Special thanks of the authors go to Prof. Rolf Zenker for his commitment to project management in the second funding period. Our thanks also go to his helpful suggestions and professional input. The authors gratefully acknowledge Dr. Karsten Rüthrich for his helpful discussions, his initial work and commitment regarding the electron beam facility. Furthermore, the authors like to thank Prof. P. Hübner for the realization of the X-ray analysis, Dipl.-Ing. G. Schade for the many tensile tests as well as G. Bittner for the hardness measurements.

\section{References}

1. R. Ahmad, R.F. Cochrane, A.M. Mullis, The formation of regular $\alpha \mathrm{Ni}-\gamma(\mathrm{Ni31Si12})$ eutectic structures from undercooled Ni-25 at.\% Si melts. Intermetallics 22, 55-61 (2012). https://doi. org/10.1016/j.intermet.2011.10.021

2. J. Ahn, E. He, L. Chen, J. Dear, C. Davies, The effect of Ar and He shielding gas on fibre laser weld shape and microstructure in AA 2024-T3. J. Manuf. Process. 29, 62-73 (2017). https:// doi.org/10.1016/j.jmapro.2017.07.011

3. C.G. Aneziris, W. Schärfl, H. Biermann, U. Martin, Energy-absorbing TRIP-steel/Mg-PSZ composite honeycomb structures based on ceramic extrusion at room temperature. Int. J. Appl. Ceram. Technol. 6(6), 727-735 (2009). https://doi.org/10.1111/j.1744-7402.2008.02321.x

4. C. Baumgart, D. Ehinger, C. Weigelt, L. Krüger, C.G. Aneziris, Comparative study of TRIP/TWIP assisted high density composite honeycomb structures under compressive load. Compos. Struct. 136, 297-304 (2016). https://doi.org/10.1016/j.compstruct.2015.09.053

5. P. Berger, H. Hügel, A. Hess, R. Weber, T. Graf, Understanding of humping based on conservation of volume flow. Phys. Proc. 12, 232-240 (2011). https://doi.org/10.1016/j.phpro.2011. 03.030

6. H. Biermann, U. Martin, C.G. Aneziris, A. Kolbe, A. Müller, W. Schärfl, M. Herrmann, Microstructure and compression strength of novel TRIP-steel/Mg-PSZ composites. Adv. Eng. Mater. 11(12), 1000-1006 (2009). https://doi.org/10.1002/adem.200900210

7. V. Braga, R.A.d.F. Mansur, R.H.M.d. Siqueira, M.S.F.d. Lima, Formability of in-situ Austempered transformation-induced plasticity steels after laser beam welding. Soldagem \& Inspeção 23(3), 402-412 (2018). https://doi.org/10.1590/0104-9224/si2303.09

8. A. Buchwalder, K. Rüthrich, R. Zenker, H. Biermann, Electron Beam welding of high alloy CrMnNi cast steels with TRIP/TWIP effect. Adv. Eng. Mater. 15(7), 566-570 (2013). https:// doi.org/10.1002/adem.201200355

9. I. Calliari, M. Dabalà, M. Penasa, Pulsed Nd-YAG laser welding of MMCs. Adv. Eng. Mater. 2(10), 653-656 (2000). https://doi.org/10.1002/1527-2648(200010)2:10<653::AIDADEM653>3.0.CO;2-Q

10. H.C. Chen, A.J. Pinkerton, L. Li, Fibre laser welding of dissimilar alloys of Ti-6Al-4V and Inconel 718 for aerospace applications. Int. J. Adv. Manuf. Technol. 52(9-12), 977-987 (2011). https://doi.org/10.1007/s00170-010-2791-3

11. Deutsches Institut für Normung e.V.: Schweißbarkeit-Metallische Werkstoffe-Allgemeine Grundlagen (2007-04-01)

12. T.K. Gupta, F.F. Lange, J.H. Bechtold, Effect of stress-induced phase transformation on the properties of polycrystalline zirconia containing metastable tetragonal phase. J. Mater. Sci. 13(7), 1464-1470 (1978). https://doi.org/10.1007/BF00553200

13. L. Halbauer, A. Buchwalder, R. Zenker, H. Biermann, Influence of EB parameters on the microstructure and mechanical properties of dissimilar welded joints in high alloy TRIP/TWIP steels, in JOM18 Conference Proceedings (JOM Institute for the Joining of Materials, 2015) 
14. L. Halbauer, A. Buchwalder, R. Zenker, H. Biermann, The influence of dilution on dissimilar weld joints with high-alloy TRIP/TWIP steels. Weld. World 60(4), 645-652 (2016). https:// doi.org/10.1007/s40194-016-0324-x

15. L. Halbauer, R. Laubstein, M. Radajewski, A. Buchwalder, L. Krüger, H. Biermann, Electron beam welding and characterization of dissimilar joints with TWIP matrix composites. Adv. Eng. Mater. 114, 1800586 (2018). https://doi.org/10.1002/adem.201800586

16. L. Halbauer, P. Proksch, A. Buchwalder, R. Zenker, H. Biermann, Joining of TWIP-matrix composites by electron beam brazing. Weld. World 62(1), 19-27 (2018). https://doi.org/10. 1007/s40194-017-0519-9

17. B. Huang, X. Chen, S. Pang, R. Hu, A three-dimensional model of coupling dynamics of keyhole and weld pool during electron beam welding. Int. J. Heat Mass Transf. 115, 159-173 (2017). https://doi.org/10.1016/j.ijheatmasstransfer.2017.08.010

18. R. Hunag, S. Chen, J.C. Huang, Electron and laser beam welding of high strain rate superplastic Al-6061/SiC composites. Metall. Mater. Trans. A 32A, 2575-2584 (2001)

19. H. Inoue, T. Koseki, Clarification of solidification behaviors in austenitic stainless steels based on welding process. Nippon Steel Tech. Rep. 95, 62-70 (2007)

20. A. Jahn, Einfluss der Martensitbildung auf die mechanischen Eigenschaften von ein- und mehrphasigen gegossenen und warm gewalzten Cr-Mn-Ni Stählen. Doctoral thesis, Technische Universität Bergakdemie Freierg, Freiberg, Germany, 2012

21. N. Kapustka, C. Conrardy, S. Babu, C. Albright, Effect of GMAW process and material conditions on DP 780 and TRIP 780 welds. Weld. Res. Suppl. 87(6), 135-148 (2008)

22. M.I. Khan, M.L. Kuntz, Y. Zhou, Effects of weld microstructure on static and impact performance of resistance spot welded joints in advanced high strength steels. Sci. Technol. Weld. Join. 13(3), 294-304 (2008). https://doi.org/10.1179/174329308X271733

23. C.J. Lippold, W.F. Savage, Solidification of austenitic stainless steel weldments: part 2-the effect of alloy composition on ferrite morphology. Weld. Res. Suppl. 2, 48-58 (1980)

24. X. Liu, M. Lin, S. Yang, J. Ruan, C. Wang, Experimental investigation of phase equilibria in the Ni-Cr-Si ternary system. J. Phase Equilib. Diffus. 35(3), 334-342 (2014). https://doi.org/ 10.1007/s11669-014-0279-9

25. V. Lopez, A. Reyes, P. Zambrano, Effect of the Heat input in the transformation of retained austenite in advanced steels of transformation induced plasticity (TRIP) welded with gas metal arc welding. Appl. Mech. Mater. 339, 700-705 (2013). https://doi.org/10.4028/www.scientific. net/AMM.339.700

26. V.H. López Cortéz, G.Y. Pérez Medina, F.A. Reyes Valdéz, H.F. López, Effects of the heat input in the mechanical integrity of the welding joints welded by GMAW and LBW process in transformation induced plasticity steel (TRIP) used in the automotive industry. Soldagem \& Inspeção 15(3), 234-241 (2010). https://doi.org/10.1590/S0104-92242010000300010

27. L.1. Ma, Y.H. Wei, L.F. Hou, C.1. Guo, Evaluation on fatigue performance and fracture mechanism of laser welded TWIP steel joint based on evolution of microstructure and micromechanical properties. J. Iron Steel Res. Int. 23(7), 677-684 (2016). https://doi.org/10.1016/S1006706X(16)30105-4

28. S. Martin, S. Richter, S. Decker, U. Martin, L. Krüger, D. Rafaja, Reinforcing mechanism of Mg-PSZ particles in highly-alloyed TRIP steel. Steel Res. Int. 82(9), 1133-1140 (2011). https://doi.org/10.1002/srin.201100099

29. S. Martin, S. Wolf, U. Martin, L. Krüger, D. Rafaja, Deformation mechanisms in austenitic TRIP/TWIP steel as a function of temperature. Metall. Mater. Trans. A 47(1), 49-58 (2016). https://doi.org/10.1007/s11661-014-2684-4

30. G.P. Medina, H.L. Ferreira, P.Z. Robledo, A.M. Pérez, F.A.R. Valdés, Microstructural development in a TRIP-780 Steel joined by friction stir welding (FSW): quantitative evaluations and comparisons with EBSD predictions. Soldagem \& Inspeção 21(2), 146-155 (2016). https:// doi.org/10.1590/0104-9224/SI2102.04

31. L. Mujica, S. Weber, C. Thomy, F. Vollertsen, Microstructure and mechanical properties of laser welded austenitic high manganese steels. Sci. Technol. Weld. Join. 14(6), 517-522 (2009). https://doi.org/10.1179/136217109X434243 
32. L. Mújica Roncery, Development of high-strength corrosion-resistant austenitic TWIP steels with C+N. Doctoral thesis, Ruhr-Universität Bochum, Bochum, Germany, 2010

33. L. Mújica Roncery, S. Weber, W. Theisen, Welding of twinning-induced plasticity steels. Scripta Mater. 66(12), 997-1001 (2012). https://doi.org/10.1016/j.scriptamat.2011.11.041

34. S. Nayak, V. Baltazar Hernandez, Y. Okita, Y. Zhou, Microstructure-hardness relationship in the fusion zone of TRIP steel welds. Mater. Sci. Eng. A 551, 73-81 (2012). https://doi.org/10. 1016/j.msea.2012.04.096

35. J. Niu, L. Pan, M. Wang, C. Fu, X. Meng, Research on laser welding of aluminum matrix composite $\mathrm{SiCw} / 6061$. Vacuum 80(11-12), 1396-1399 (2006). https://doi.org/10.1016/j.vacuum. 2006.01.023

36. G.B. Olson, M. Cohen, A mechanism for the strain-induced nucleation of martensitic transformations. J. Less Common Metals 28, 107-118 (1972)

37. M. Onyuna, H. Oettel, U. Martin, A. Weiß, On the deformation behavior and martensitic transformations of metastable austenitic steels. Adv. Eng. Mater. 6, 529-535 (2004)

38. S. Pichumani, R. Srinivasan, V. Ramamoorthi, Mechanical properties, thermal profiles, and microstructural characteristics of $\mathrm{Al}-8 \% \mathrm{SiC}$ composite welded using pulsed current TIG welding. J. Mech. Sci. Technol. 32(4), 1713-1723 (2018). https://doi.org/10.1007/s12206018-0130-4

39. P. Podany, M. Koukolikova, T. Kubina, R. Prochazka, A. Franc, Fe-Mn(Al, Si) TWIP steelstrengthening characteristics and weldability. IOP Conf. Ser. Mater. Sci. Eng. 179, 012057 (2017). https://doi.org/10.1088/1757-899X/179/1/012057

40. P. Podany, C. Reardon, M. Koukolikova, R. Prochazka, A. Franc, Microstructure, mechanical properties and welding of low carbon. Medium manganese TWIP/TRIP steel. Metals 8(4), 263 (2018). https://doi.org/10.3390/met8040263

41. D. Rafaja, C. Krbetschek, C. Ullrich, S. Martin, Stacking fault energy in austenitic steels determined by using in situ X-ray diffraction during bending. J. Appl. Crystallogr. 47(3), 936947 (2014). https://doi.org/10.1107/S1600576714007109

42. U. Reisgen, M. Schleser, O. Mokrov, E. Ahmed, Numerical and experimental investigation of tensile behavior of laser beam welded TRIP700 steel. ISIJ Int. 51(3), 429-434 (2011). https:// doi.org/10.2355/isijinternational.51.429

43. L. Remy, A. Pineau, Twinning and strain-induced F.C.C. $\rightarrow$ H.C.P. transformation in the FeMn-Cr-C system. Mater. Sci. Eng. 28(1), 99-107 (1977)

44. D.C. Saha, Y. Cho, Y.D. Park, Metallographic and fracture characteristics of resistance spot welded TWIP steels. Sci. Technol. Weld. Join. 18(8), 711-720 (2013). https://doi.org/10.1179/ 1362171813Y.0000000151

45. K. Sato, M. Ichinose, Y. Hirotsu, Y. Inoue, Effects of deformation induced phase transformation and twinning on the mechanical properties of austenitic Fe-Mn-Al alloys. ISIJ Int. 29(10), 868877 (1989)

46. P.J. Spencer, J.N. Pratt, A study of the vapour pressure of manganese using a new hightemperature torsion—effusion apparatus. Brit. J. Appl. Phys. 18(10), 1473-1478 (1967). https:// doi.org/10.1088/0508-3443/18/10/314

47. S. Subramanian, D.A. Muller, J. Silcox, S.L. Sass, Chemistry, bonding and fracture of grain boundaries in Ni3Si. Acta Metall. 45(9), 3565-3571 (1997)

48. N. Suutala, T. Takalo, T. Moisio, Ferritic-austenitic solidification mode in austenitic stainless steel welds. Metall. Mater. Trans. A 11A, 717-725 (1980)

49. N. Suutala, T. Takalo, T. Moisio, Ferritic-austenitic solidification mode in austenitic stainless steel welds. Metall. Trans. A 11(5), 717-725 (1980). https://doi.org/10.1007/BF02661201

50. J. Talonen, Effect of strain-induced $\alpha$ '-martensite transformation on mechanical properties of metastable austenitic stainless steels. Ph.D. thesis, Helsinki University of Technology, Helsinki, Finland, 2007

51. D.N. Trushnikov, G.M. Mladenov, V.Y. Belenkiy, E.G. Koleva, S.V. Varushkin, Current-driven ion-acoustic and potential-relaxation instabilities excited in plasma plume during electron beam welding. AIP Adv. 4(4), 047105 (2014). https://doi.org/10.1063/1.4870944 
52. K.H. Tseng, Study on surface appearance, geometry size, and delta-ferrite content of ZrO2aided TIG welding of AISI 316LN stainless steel. Int. J. Adv. Manuf. Technol. 89(5-8), 23552362 (2017). https://doi.org/10.1007/s00170-016-9280-2

53. C. Weigelt, H. Berek, C.G. Aneziris, R. Eckner, L. Krüger, Joining of Zirconia reinforced metal-matrix composites. Mater. Sci. Forum 825-826, 498-505 (2015). https://doi.org/10. 4028/www.scientific.net/MSF.825-826.498

54. C. Weigelt, G. Schmidt, C.G. Aneziris, R. Eckner, D. Ehinger, L. Krüger, C. Ullrich, D. Rafaja, Compressive and tensile deformation behaviour of TRIP steel-matrix composite materials with reinforcing additions of zirconia and/or aluminium titanate. J. Alloys Compd. 695, 9-20 (2017). https://doi.org/10.1016/j.jallcom.2016.10.176

55. M. Wendler, A. Weiß, L. Krüger, J. Mola, A. Franke, A. Kovalev, S. Wolf, Effect of manganese on microstructure and mechanical properties of cast high alloyed $\mathrm{CrMnNi}-\mathrm{N}$ steels. Adv. Eng. Mater. 15(7), 558-565 (2013). https://doi.org/10.1002/adem.201200318

56. J. Yoo, K. Han, Y. Park, J. Choi, C. Lee, Evaluation of solidification cracking susceptibility of Fe-18Mn-0.6C steel welds. Sci. Technol. Weld. Join. 19(6), 514-520 (2014). https://doi.org/ $10.1179 / 1362171814$ Y.0000000216

Open Access This chapter is licensed under the terms of the Creative Commons Attribution 4.0 International License (http://creativecommons.org/licenses/by/4.0/), which permits use, sharing, adaptation, distribution and reproduction in any medium or format, as long as you give appropriate credit to the original author(s) and the source, provide a link to the Creative Commons license and indicate if changes were made.

The images or other third party material in this chapter are included in the chapter's Creative Commons license, unless indicated otherwise in a credit line to the material. If material is not included in the chapter's Creative Commons license and your intended use is not permitted by statutory regulation or exceeds the permitted use, you will need to obtain permission directly from the copyright holder.

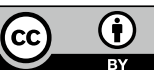

